\title{
San Ciriaco y santa Paula, patronos de Málaga, en un lienzo inédito de Pedro López Calderón
}

\section{The Patron Saints of Malaga, Ciriaco and Paula, in a hitherto Unknown Painting by Pedro López Calderón}

Artículo recibidoel 5 de febrero de 20I8; devuelto para revisión el I8 de abril de 20I8; aceptado el 5 de octubre de 20I8, http://dx.doi.org/Io.2220I/iie.I8703062e.2019.II4.2666

José Ignacio Mayorga Chamorro Universidad de Málaga, España, mayorgach@uma.es

Líneas de investigación Arte iberoamericano; estudios iconográficos y cultura visual; arquitectura contemporánea; patrimonio cultural.

Lines of research Ibero-American art; iconographic studies and visual culture; contemporary architecture; cultural heritage.

Publicaciones más relevantes "Referentes latinoamericanos para la arquitectura malagueña del desarrollismo", Quiroga. Revista de Patrimonio Iberoamericano, núm. II (2017): 98-IO2.

Resumen Una obra hasta la fecha inédita, pintada en México por Pedro López Calderón en 1716, ha sido identificado en el templo de la Virgen de Guadalupe en San Cristóbal de las Casas Chiapas. Su descubrimiento aporta nuevos datos y permite reunir las escasas y dispersas referencias de la vida del artista. El análisis de la temática del cuadro, los santos mártires Ciriaco y Paula, patronos de la ciudad de Málaga, España aborda la migración de una iconografía marcadamente local, así como su adaptación e interpretación por un pintor novohispano.

Palabras clave Pedro López Calderón; san Ciriaco; santa Paula; mártires; Málaga; pintura novohispana.

Abstract An until now unknown canvas by Pedro López Calderón painted in Mexico in 1716 has been identified in the church of the Virgin of Guadalupe in San Cristóbal de las Casas, Chiapas. It's discovery provides new data and brings together scarce, dispersed references related to the artist's life. The analysis of the painting's main theme, Holy Martyrs Ciriaco and Paula, patron saints of Málaga, Spain addresses the migration of a markedly local iconography, as well as its adaptation and interpretation by a painter in New Spain.

Keywords Pedro López Calderón; San Ciriaco; Santa Paula; martyrs; Málaga; painting; New Spain. 


\author{
JOSÉ IGNACIO MAYORGA CHAMORRO \\ UNIVERSIDAD DE MÁLAGa, ESPAÑa
}

\title{
San Ciriaco y santa Paula, patronos de Málaga, en un lienzo inédito de Pedro López Calderón
}

\begin{abstract}
G
1 hallazgo de un lienzo inédito de la relevancia del que aquí se presenta es siempre una feliz realidad. Más aún cuando en él se combinan, con suficiente calidad plástica, aportaciones iconográficas de carácter excepcional con nueva información sobre un autor cuya figura y producción permite rescatar y conocerlo mejor. El lienzo de san Ciriaco y santa Paula, mártires de época romana y patronos de la ciudad de Málaga (Andalucía, España), ubicado en el templo de la Virgen de Guadalupe en San Cristóbal de las Casas (Chiapas, México), fue pintado y firmado en México por el pintor novohispano Pedro López Calderón en 1716 (fig. I). En él confluyen, por tanto, múltiples y complejas realidades cuyo estudio permitirá recorrer desde la Nueva España de principios del siglo XviII hasta la Malaca romana de las primitivas comunidades cristianas. Pero se toma como punto de partida aquel en el que de manera fortuita arrancó la presente investigación: el templo de la Virgen de Guadalupe en San Cristóbal de las Casas, México. El hallazgo de la obra, ubicada en el sotocoro del templo, del lado del Evangelio, se produjo de manera casual en el transcurso de otra investigación académica desarrollada en la región. Entre el heterodoxo conjunto de obras que allí se conservan, el lienzo que me ocupa destaca en calidad plástica y por su iconografía, pues aunque los santos y su martirio son un repertorio habitual en cualquier iglesia católica, la representación de Ciriaco y Paula resulta excepcional fuera de su ciudad de origen, dado lo limitado y exclusivamente local de su culto y devoción popular. Por lo demás,
\end{abstract}


conocer la fecha y autoría de la pieza ha sido fundamental en un proceso marcado por la dificultad para conseguir datos de tipo específico.

El templo de la Virgen de Guadalupe, hoy en el popular barrio al que dio origen y nombre, es un importante centro de peregrinación regional ante las imágenes de su venerada patrona. Erigido sobre una pequeña capilla de I835, el actual edificio se comenzó a construir en I854 sobre un cerro en lo que entonces eran las afueras de la villa de San Cristóbal, cuyas vistas domina. ${ }^{1}$ Pese a tratarse de una construcción decimonónica —en el aspecto arquitectónico continuadora de la tradición hispana - cuenta con un heterodoxo patrimonio artístico en el que, junto a piezas contemporáneas, abundan las pinturas de época virreinal —la mayoría anónimas y de mérito desigual— que llegaron al templo después de la construcción del mismo (figs. 2 y 3).

Lamentablemente, se desconocen los orígenes de estas piezas y en qué momento pudieron llegar allí. En la parroquia se afirma no conservar ningún documento histórico que pueda aportar información sobre el asunto, pero los feligreses y trabajadores más antiguos exponen que esos cuadros "siempre estuvieron ahî". Como dato significativo, se señala que muchos de los lienzos históricos, distribuidos en las paredes de la nave, presentan idénticos marcos dorados y de factura simple, como el del cuadro que es objeto del presente estudio. Esto nos hace deducir que todos ellos quizá fueran reenmarcados a su llegada a este templo desde su anterior origen, sea o no éste el mismo para las distintas piezas.

El Archivo Histórico Diocesano de San Cristóbal de las Casas se encontraba cerrado al público y a consultas en las fechas de la investigación por su afección estructural - junto al resto del conjunto catedralicio donde se ubica- tras el fuerte terremoto sufrido en la región el 7 de septiembre de 2017. Esto ha imposibilitado la consulta física de sus fondos, en los que quizá algún día, tras su reapertura, pueda llegar a descubrirse alguna información a este respecto. Lo cierto es que los trabajadores del archivo presentan ciertas dudas relacionadas a esta posibilidad y la consulta del catálogo en línea de sus fondos ya digitalizados tampoco ha aportado resultados hasta el momento.

La conversación con algunas de las personalidades que mejor conocen el patrimonio artístico diocesano sancristobalino - y en particular, con fray Pablo Iribarren Pascal— sugirió la hipótesis de que el origen de estas obras podría ser cualquier otro templo de la región, incluida la misma catedral de San Cristóbal,

I. Milton Tovilla Ozuna, "Templo y festividad de la Virgen de Guadalupe", Recuerdos Sancristobalinos/Cuarto Contacto, núm. 2 (2016): 3. 


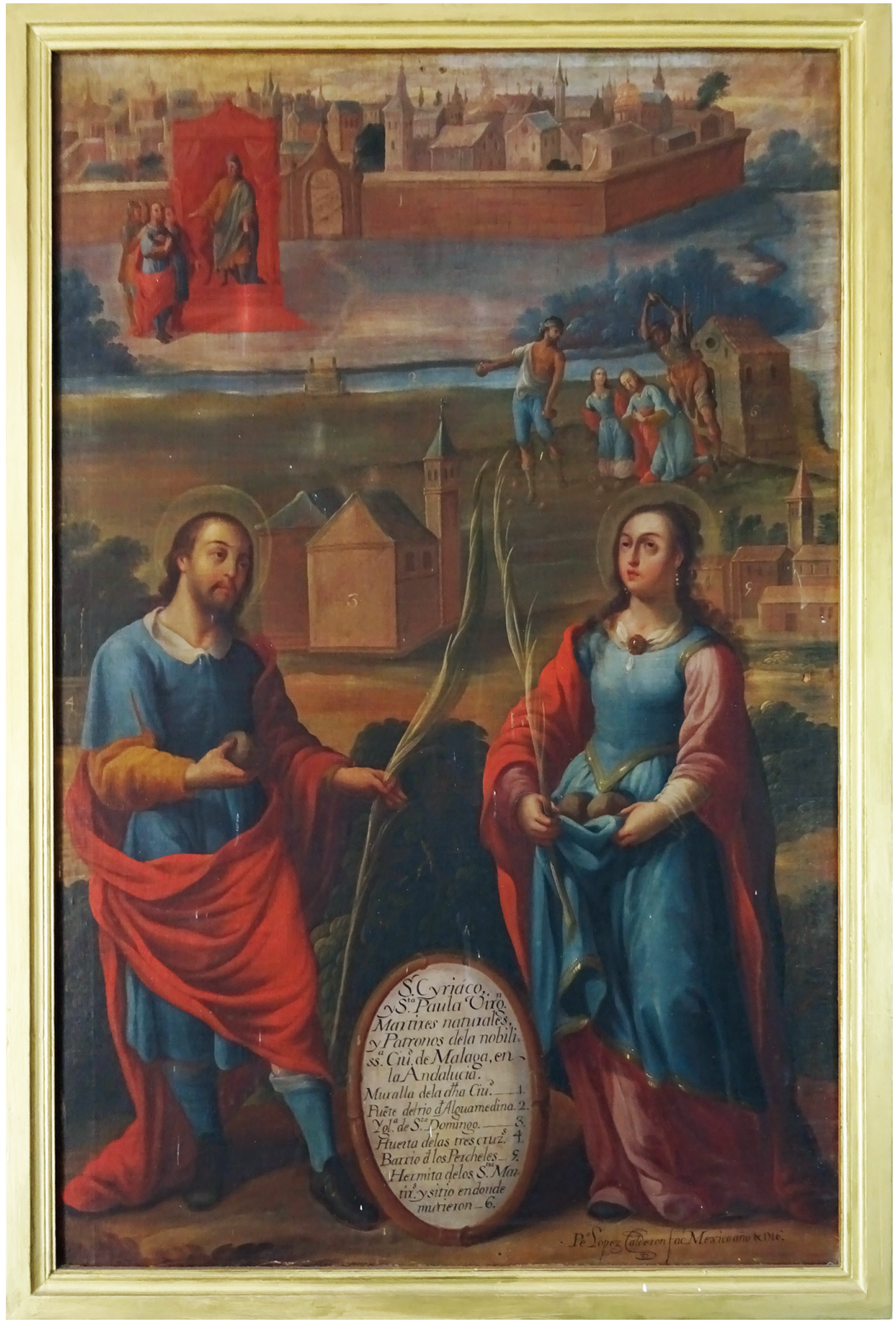

I. Pedro López Calderón, San Ciriaco y santa Paula, 1716, 96× ×48.5 cm, San Cristóbal de las Casas, México. Foto: José Ignacio Mayorga Chamorro. Secretaría de Cultura.-INAH. Méx.- "Reproducción autorizada por el Instituto Nacional de Antropología e Historia". 


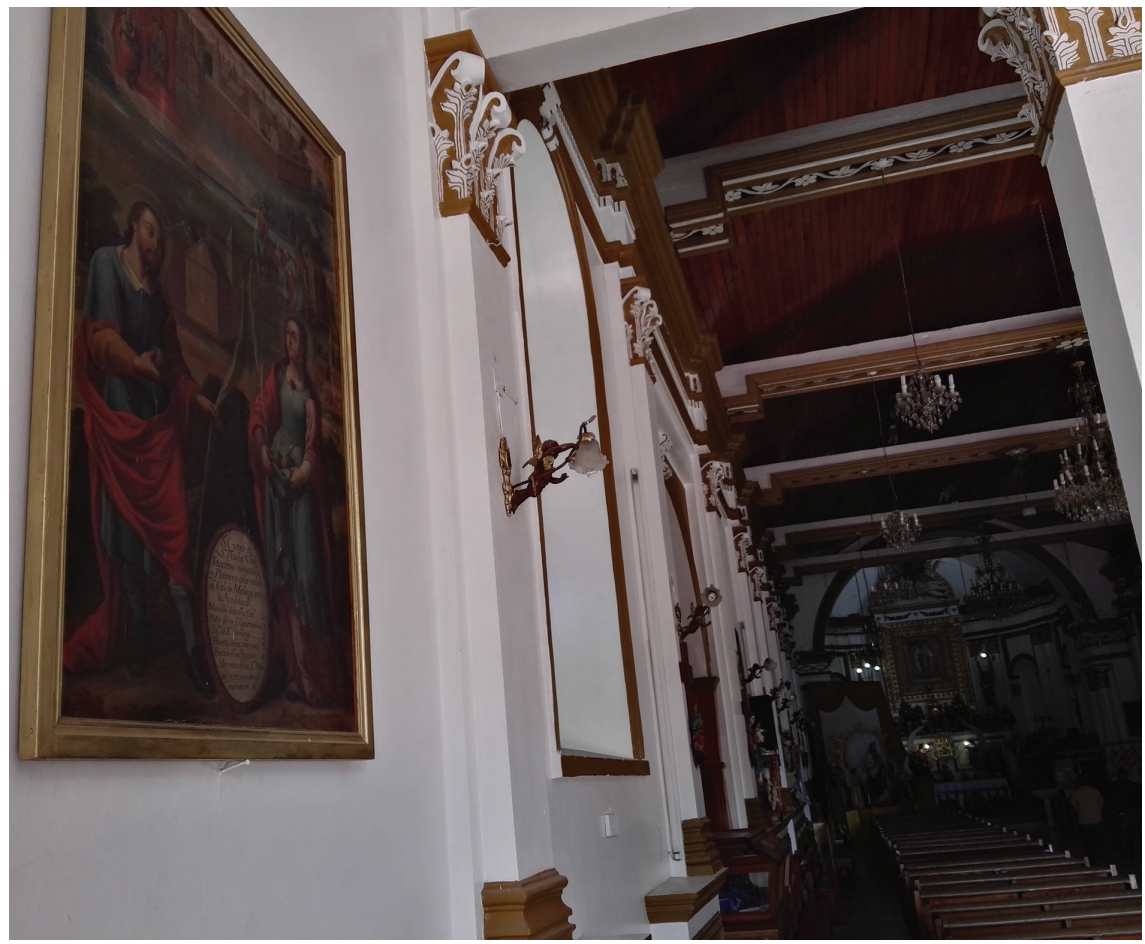

2. Interior del Templo de la Virgen de Guadalupe con el lienzo de san Ciriaco y santa Paula. San Cristóbal de las Casas. Foto: José Ignacio Mayorga Chamorro, 20I7. Secretaría de Cultura.INAH. Méx.- "Reproducción autorizada por el Instituto Nacional de Antropología e Historia".

atendiendo a la presencia documentada de otras obras ligadas a este origen en el templo guadalupano. Serían las tallas de madera de la Santísima Virgen de Guadalupe y de su siervo Juan Diego ${ }^{2}$ que en 1850 donó el entonces deán de la catedral, don Lino García. ${ }^{3}$ Por tanto, no sería de extrañar que se pudiese haber realizado una nueva donación por parte de la catedral para continuar con el adorno de este nuevo templo diocesano una vez reconstruido, hacia I864. El contexto sería favorecedor, pues hacia esas fechas, la imposición del gusto

2. Manuel Toussaint, Arte colonial en México (Ciudad de México: Universidad Nacional Autónoma de México-Instituto de Investigaciones Estéticas, 1990), I84.

3. Miguel Ángel Muñoz Luna, "Iglesia de Guadalupe", consultado el 30 de noviembre de 20I6, en https://sancristobaldelascasas.wordpress.com/2008/oI/ig/iglesia-de-guadalupe/. 


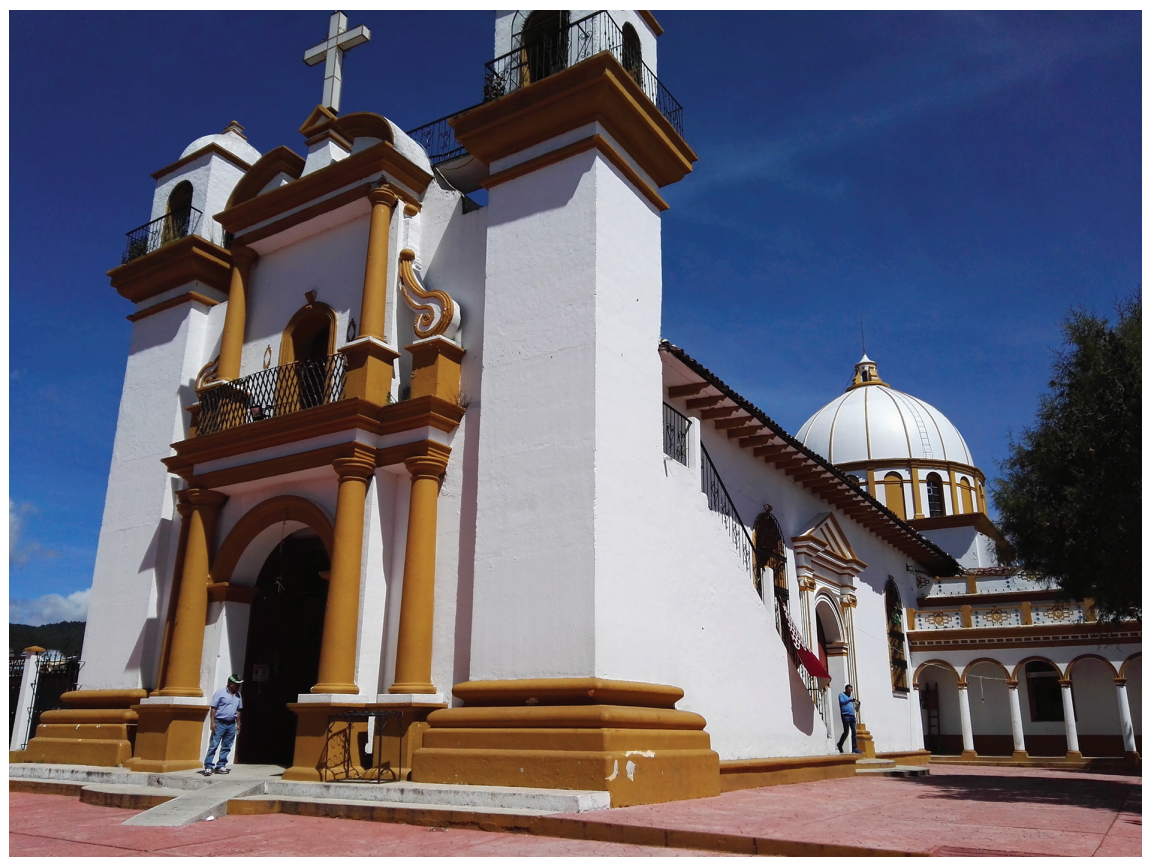

3. Fachada principal del templo de la Virgen de Guadalupe, San Cristóbal de las Casas. Foto: José Ignacio Mayorga Chamorro, 2017. Secretaría de Cultura.-INAH. Méx.- "Reproducción autorizada por el Instituto Nacional de Antropología e Historia”.

neoclásico estaba propiciando la dispersión de muchos cuadros barrocos, desmontados de algunas iglesias para acabar, con fortuna, en otras. Esta hipótesis podría aclarar también la presencia, quizá azarosa, de este lienzo de Pedro López Calderón en una región en la que hasta el presente hallazgo no se tenía documentada obra suya. Aunque al tratarse de un maestro pintor con taller propio en la Ciudad de México, bien pudo producir la obra por encargo, desde allí, para la entonces denominada Ciudad Real de Chiapa o para cualquier otro destino.

En cualquier caso, en lo relativo al origen de la pieza parece ser más vinculante descubrir quién pudo ser su promotor que el lugar de procedencia física de la misma, aunque ambos factores pudieran estar conectados. Sin embargo, la identidad del comitente se mantiene en el misterio por el momento, ante la ausencia de fuentes documentales. No obstante, diversos motivos que más 
adelante expondré me llevan a deducir que debió tratarse de algún malagueño que, asentado en la Nueva Espańa, hiciera fortuna y quisiera encargar un recordatorio de su ciudad natal y sus santos patronos, bien para su residencia particular o bien como donación a algún templo o capilla. Algunos datos complementarios que podrían soportar mi suposición sería el del tamaño, la calidad y el estado de conservación de la pieza.

El lienzo tiene unas dimensiones de $\mathrm{I} 48.5 \times 96 \mathrm{~cm}$ montado en el bastidor, $\mathrm{y}$ unos $160.5 \times 108 \mathrm{~cm}$ con su marco actual. Un tamańo medio, pero considerable, que en la época se vincularía a un presupuesto en proporción. Además, está firmado por un maestro pintor de reconocido prestigio en su momento, que realizaba importantes encargos para órdenes religiosas, lo que habla de nuevo de la solvencia de su comitente.

Por último, me detengo en su buen estado de conservación, que permite descartar un posible culto público de la obra en su origen y optar por el de una residencia u oratorio particular. Ello explicaría que aunque su barniz presente cierto oscurecimiento propio del paso del tiempo, su superficie no esté ennegrecida por el humo de las velas como ocurre en muchos otros de los cuadros de época virreinal localizados en este mismo templo. Como tampoco muestra las importantes disgregaciones de capa pictórica que suelen ser habituales en la parte baja de las pinturas cuando se encuentran expuestas al calor de las candelas o a la excesiva humedad.

Respecto a otras alteraciones, hoy día se localizan algunas manchas de pintura blanca dispuestas en forma aleatoria sobre la superficie pictórica que quizá sean salpicaduras de algún pintado reciente de las paredes o techos circundantes. Por último, hay pequeños desgarres y roturas en distintos puntos del lienzo, posiblemente accidentales, que no perturban la percepción de la pieza ni comprometen su estado de conservación, bastante bueno (fig. 4).

En la parte inferior derecha del lienzo se conserva - por fortuna y en excelente estado- una inscripción autógrafa del pintor, que recoge su firma y el lugar y la fecha en que la pintó del modo que sigue: "Peo Lopez Calderon fact. Mexico año de 1716 ". La analizaré por partes siguiendo las anotaciones del profesor Abelardo Carrillo y Gariel, cuyo trabajo al respecto es una referencia. En el mismo se catalogan algunos ejemplos de la firma de López Calderón, aunque muy brevemente y sin proceder a su análisis (fig. 5). ${ }^{4}$

4. Abelardo Carrillo y Gariel, Autógrafos de pintores coloniales (Ciudad de México: Universidad Nacional Autónoma de México-Instituto de Investigaciones Estéticas, 1972), 74-75. 
4. Pedro López Calderón, San Ciriaco y santa Paula (detalle del estado de conservación). Foto: José Ignacio Mayorga Chamorro. Secretaría de Cultura.-INAH.

Méx.- "Reproducción autorizada por el Instituto Nacional de Antropología e Historia”.

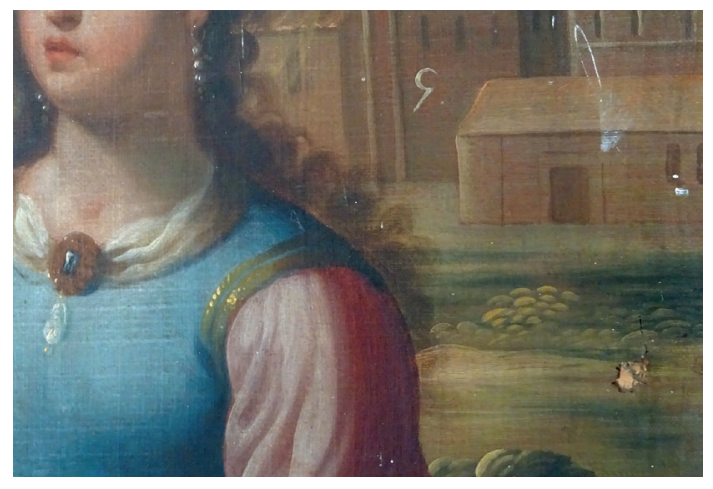

Como consideración inicial, se puede resumir que la firma presente en este lienzo responde en sus características a un modo de proceder común entre los pintores novohispanos del momento. Sirva como primer ejemplo su ubicación, en la parte más baja del lienzo y hacia la derecha, que suele ser lugar frecuente para estas inscripciones por su fácil visibilidad, una vez colgado el soporte. Concretamente se dispone bajo los pies de santa Paula, sobre el fondo marrón y plano que correspondería al suelo, y en letras oscuras de gran tamaño que permiten su perfecta lectura.

Su grafía respondería al tipo de letra llamado "con adorno", que ornamenta las mayúsculas iniciales y, por lo general, la primera letra del colofón, cuando lo lleva, junto a algunas minúsculas señaladas. Así ocurre, en particular, en la "C" mayúscula que inicia su apellido, Calderón, y que será una marca distintiva y sello personal de la firma de este pintor, repitiéndola en la mayoría de las distintas variaciones de su rúbrica. Su elaborado trazo se conecta con el de la "D" intermedia en la parte elevada, y termina en una espiral en su tramo bajo, dando una muestra de inventiva y de habilidad en el dibujo que quizá sea intencionada y causa de su repetición. La "L" inicial de López, por su parte, presenta un diseño más sencillo al empleado en otras ocasiones, en las que conecta su trazo horizontal con los amplios desarrollos de la " $Z$ ” final. Por último destacaría el pequeño remate transversal con que concluye el asta descendente de la " $\mathrm{P}$ " de López y de la $\mathrm{F}$ de $\mathrm{fac}^{\mathrm{t}}$., que también va a mantener en otras de sus firmas.

La que se encuentra aquí es, quizá, una de las versiones más completas de su rúbrica, iniciándola con su nombre, Pedro, abreviado como $\mathrm{Pe}^{\mathrm{o}}$, y seguida de sus dos apellidos: López Calderón, sin los acentos que les corresponden. Este aspecto es relevante, porque el hecho de que ocasionalmente firme sólo con su 
segundo apellido - Calderón — o como Po. Calderón, ha generado bastante confusión entre algunos historiadores, como analizaré más adelante.

Tras su nombre y apellidos, el pintor incluye en su autografía el colofón "fact. Mexico" (lo hacía en México), en una incongruente combinación del pretérito imperfecto latino faciebat con el castellano México, en lugar de continuar con el latín Mexici, que en cualquier caso no altera su significado. Al optar por esta locución latina, el autor pretendía mostrar su obra como algo imperfecto o inacabado, aportando un matiz de significado que lo diferencia de otros colofones concebidos en tiempos perfectos, como Pinxit Mexici (pintado en México) o el más habitual Fecit Mexici (hecho en México). Todos ellos, en sus formas completas o abreviadas, fueron un elemento característico de la pintura de la Nueva España en el siglo Xviır. Sobre todo entre los pintores más aventajados y con identidad propia, como refuerzo que expresaba, junto a la firma, su carácter creador.

Pero el aspecto más relevante de estas inscripciones quizá sea la referencia geográfica al lugar de su producción: México, como se conocía a la ciudad capital del virreinato novohispano. Tras su inclusión latería la seña voluntaria de identidad de unos pintores que, ya en el siglo xviII, empiezan a ser conscientes de sus propios logros y aportaciones, y que se distinguen así no sólo de los modelos europeos que por tradición habían actuado como referentes, sino también de otras provincias novohispanas o de los otros virreinatos americanos, a donde, como a España, se estaban exportando buen número de obras. ${ }^{5}$

La inscripción concluye, por último, con "año de 1716 ", recurriendo a una manera extensa de datar la obra dentro de la firma. Pero el dato sustancial lo aporta la fecha en sí, ya que se trataría de la primera obra datada de Pedro López Calderón, según se viene investigando en el acercamiento a la trayectoria del pintor. La siguiente obra localizada hasta el momento es un San Felipe Neri de I7I8 que el profesor Raúl Figueroa Esparza ha localizado en el templo de San Juan Nepomuceno de Aguascualientes. ${ }^{6}$ A partir de ahí, el número de obras

5. Luisa Elena Alcalá Donegani, Jaime Cuadriello Aguilar, Paula Mues Orts y Ronda Kasl, Pintado en México, I700-I79o, Pinxit Mexici, Ilona Katzew, coord., catálogo de la exposición (Ciudad de México: Fomento Cultural Banamex/Los Angeles County Museum of Art, 20I7) (en la Ciudad de México la exposición se celebró en el Palacio de Cultura Citibanamex-Palacio de Iturbide, del 28 de junio de 2017 al I5 de octubre de 20I7).

6. Raúl Figueroa Esparza, "La religión católica a través de la pintura en el Aguascalientes virreinal (I675-I82I)", tesis de Doctorado (Aguascalientes: Universidad Autónoma de Aguascalientes, 20II), I28. 


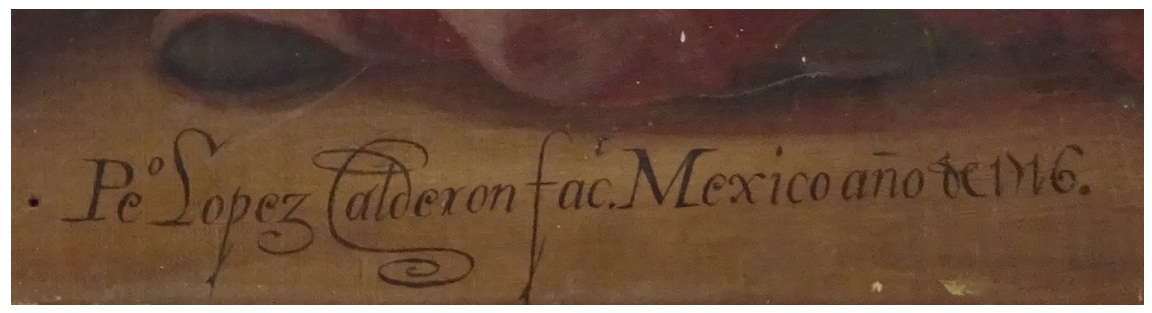

5. Pedro López Calderón, San Ciriaco y santa Paula (detalle de la firma). Foto: José Ignacio Mayorga Chamorro. Secretaría de Cultura.-INAH. Méx.- "Reproducción autorizada por el Instituto Nacional de Antropología e Historia”.

localizadas y fechadas aumenta de manera considerable en los primeros ańos de la década de 1720 , cuando parece obtener un importante número de encargos para templos de la Ciudad de México principalmente, siempre de temática religiosa.

Así, la presente aportación amplía el espectro cronológico que abarcaría su trabajo, adelantándolo en unos años a las fechas dadas por investigadores como Abelardo Carrillo y Gariel, que en la obra citada incluye, dentro del índice onomástico final, la siguiente referencia: "Nombre: López Calderón, Pedro. / Lugares en que pintó y fechas de sus trabajos: México, I719-1755 / Referencias bibliográficas y observaciones: ninguna". ${ }^{7}$

Pero Pedro López Calderón no siempre incluyó la fecha cuando firmó sus obras, por lo que se puede concluir el análisis de esta inscripción autógrafa subrayando el hecho de que se trata de una de las más completas realizada por el autor. Éste, como también fuera relativamente habitual entre los pintores novohispanos de su época, no siempre firmó de la misma manera ni con la misma grafía ni tampoco aportó siempre los mismos datos. ${ }^{8} \mathrm{El}$ análisis de las distintas y heterodoxas firmas localizadas hasta el momento queda aún pendiente de un estudio más profundo, pero hoy es posible detenerse en la cuestión del nombre, por lo paradójico y complejo para la investigación.

En el cuadro de San Ciriaco y santa Paula se leen con claridad sus dos apellidos, siendo ésta la solución más frecuente. Pero en no pocas ocasiones se excluye el primero de ellos para reducir la firma a "Pedro Calderón". El nombre, en

7. Carrillo y Gariel, Autógrafos, 158.

8. Carrillo y Gariel, Autógrafos, io. 
cualquiera de los dos casos, puede y suele aparecer abreviado como "Pe", "Po." o "P.", pero puede incluso desaparecer cuando se prescinde también del primer apellido. Tal omisión es significativa, al haber causado una importante confusión en algunos investigadores que los han considerado o catalogado como personas distintas. Sirva de ejemplo el caso de Manuel Toussaint, que los refiere siempre por separado, pero a la vez señala que Pedro Calderón "Parece ser el mismo pintor Pedro López Calderón que menciona Couto"9 o que ignora "si será el mismo artista que se llama Pedro López Calderón". ${ }^{\text {Io }}$

En mi caso, creo que todos los lienzos corresponden a una misma persona, lo que explicaría las coincidencias en la caligrafía de las firmas, en su estilo, ámbito temporal y de localización. Además, el empleo indistinto de los dos apellidos o sólo del más identificativo de ellos no es extraño dentro de la cultura artística hispánica. ${ }^{\mathrm{II}}$

También se debe considerar el hecho de que, como maestro pintor, Pedro López Calderón contara con un taller propio y con la consiguiente colaboración de segundas manos entre sus aprendices. Este sistema de producción podría explicar las mencionadas diferencias en la firma, pero sobre todo, podrían justificar la irregular calidad de sus creaciones.

Algunos de los primeros autores que abordaron su obra analizaron ejemplos que consideraron - quizá merecidamente- "de muy poca importancia", I2 repitiendo las mismas referencias a unos lienzos de factura poco destacada. Son pequeńos cuadros de temática religiosa para estancias menores de iglesias y conventos, de los que se encuentra cierto número en la Ciudad de México.

Pero estas afirmaciones no deberían extenderse al conjunto de la obra del autor, sobre todo a raíz de otros lienzos que después se le han ido atribuyendo. Así, investigaciones como la que aquí presento o como la desarrollada por José Armando Hernández Soubervielle ${ }^{13}$ están sacando a la luz un conjunto de obras de relativo mérito estético o intelectual que han revelado a un pintor cada vez más interesante y complejo. Lo mismo se deduce de otras obras que se han

9. Toussaint, Arte colonial, I25.

Io. Manuel Toussaint, Pintura colonial en México (Ciudad de México: Universidad Nacional Autónoma de México-Instituto de Investigaciones Estéticas, 1990), I50-I52.

II. Carrillo y Gariel, Autógrafos, II-I2.

I2. Agustín Fernández Villa, Breves apuntes sobre la antigua escuela de pintura en México (Guadalajara, México: UNED, 1990), 29.

I3. José Armando Hernández Soubervielle, "El celo espiritual y militar de la orden franciscana y la monarquía hispánica en una pintura de la Inmaculada de Pedro López Calderón”, Archivo Español de Arte 84, núm. 336 (20II): 337-354. 
podido localizar y estudiar como complemento a esta investigación, incluyendo nuevos casos inéditos, cuyo estudio está en curso. ${ }^{\mathrm{I}}$

De este modo podemos llegar a afirmar que la obra de Pedro López Calderón es mucho más amplia de lo que hasta la fecha se ha venido refiriendo, pero que se encuentra muy dispersa y que ha sido en muy pocos casos estudiada con profundidad. Y aunque su calidad sea irregular, los ejemplos de mérito son cada vez más numerosos según se va avanzando en su conocimiento.

Menos avances se han realizado sobre la biografía de este pintor "del que poco se sabe", ${ }^{\text {I5 }}$ cuya vida se ha considerado tradicionalmente un completo misterio. En el marco de la presente investigación se ha recopilado toda la bibliografía en la que, desde finales del siglo xIx hasta fechas recientes, se ha nombrado y dado a conocer muy poco a poco algunos datos de su vida y su obra. Referirlas y analizarlas todas sería motivo de una nueva publicación, pero se puede concluir que todas ellas aportan y se basan siempre en las mismas escasas referencias, reafirmando con ello lo desconocido del autor y de su producción. No obstante, la feliz agrupación de todas las que he podido localizar, me permite reconstruir de manera más completa el perfil de un artista del que aún queda mucho por descubrir.

Se desconoce la fecha y el lugar de nacimiento de Pedro López Calderón, al que se supone mexicano y nacido en la segunda mitad del siglo XVII, atendiendo a las fechas de su producción. Por tradición se ha enmarcado su obra en la primera mitad del siglo xviII, siendo el primer lienzo fechado que se conoce hasta la fecha el de los santos Ciriaco y Paula que aquí comento, de I7i6. Pero, recientes aportaciones ${ }^{16}$ - posiblemente desconocedoras del alcance de sus revelaciones - lo han datado activo desde finales del siglo Xviı en Oaxaca, donde se le suponen obras "de mucha abundancia" ${ }^{17}$ de las que pocas conoce-

I4. "Fac ${ }^{(+)}$. México: el pintor novohispano Pedro López Calderón", tesis de doctorado del autor de este artículo, matriculada dentro del Programa de Doctorado en Estudios Avanzados en Humanidades de la Universidad de Málaga, que tiene entre sus objetivos el estudio monográfico de la obra y figura de Pedro López Calderón.

15. Gabriela García Lascurain Vargas, "Noticias acerca de pinturas y pintores de enconchados en Oaxaca", Anales del Instituto de Investigaciones Estéticas XXXIII, núm. 98 (20II): 264.

16. García Lascurain Vargas, "Noticias acerca de pinturas y pintores de enconchados en Oaxaca", 264.

17. José Bonequi, Noticias sobre los pintores y escultores que han ejecutado obras en la capital y en algunos lugares del estado de Oaxaca, Oaxaca, Biblioteca Francisco de Burgoa-Fondo Luis Castañeda Guzmán, doc. inédito 36/539 c.I9, I y 3. 
mos. Allí se le documenta en I692 y I698 como maestro pintor, aceptando a dos jóvenes como aprendices.

Sus últimos trabajos fechados datarían de la década de 1730, aunque su periodo de mayor producción registrada sería la década de 1720 a 1730. Para entonces, tendría su centro principal de producción en la Ciudad de México, incluyendo con frecuencia junto a su firma la inscripción "fact. Mexico" o algunas de sus variantes. Pero gran parte de sus obras se encuentran dispersas por diferentes regiones de la geografía mexicana, sobre todo al noroeste de la capital, hallándose en lugares como San Luis Potosí, ${ }^{18}$ Aguascalientes, ${ }^{19}$ Guadalajara, ${ }^{20}$ o Pánuco de Coronado" (municipio del estado de Durango) ${ }^{2 \mathrm{I}}$ algunos de sus trabajos. Aunque su ejecución pudo requerir su desplazamiento en algunas ocasiones, buena parte de ellos hubo de ser producida en su taller y desde allí exportada hasta sus diferentes destinos nacionales e internacionales.

Poco conocida en México ha sido su faceta de pintor de cuadros de la Virgen de Guadalupe, que debió exportar en buen número a España. En Sevilla se han localizado seis iconografías guadalupanas con su firma, ${ }^{22}$ tres de las cuales han recibido recientes y más profundos estudios. ${ }^{23} \mathrm{E}$ igualmente asombra su faceta como pintor de enconchados, desvelada por expertos en la materia que le atribuyen Nacimiento de la Virgen firmado en $1723 .{ }^{24}$ Esta labor, poco referida

18. Rafael Morales Bocardo, El convento de San Francisco de San Luis Potosí: casa capitular de la provincia de Zacatecas (San Luis Potosí: Archivo Histórico del Estado de San Luis Potosí, I997), 490.

19. Figueroa Esparza, "La religión católica", I28-I29.

20. Rogelio Barba Jiménez, Rosalba Campos Carranza, María Castañeda Delgado y Ana Paula García Flores, "El restaurador como detective: El caso de la Virgen del Rosario de Pedro López Calderón”, en IX Foro Académico de Ciencia, creación y restauración (Ciudad de México: Escuela de Conservación y Restauración de Occidente, 2 de noviembre de 20I2), consultado el 3 de enero de 20I8, en http://www.ecro.edu.mx/pdf/pdf_memorias/maria_castaneda.pdf.

2I. Javier Guerrero Romero, "Un patrimonio desconocido", consultado el I6 de noviembre de 20I7, en http://www.elsiglodedurango.com.mx/noticia/ro550.un-patrimonio-desconocido.html.

22. Joaquín González Moreno, Iconografía guadalupana I (Ciudad de México: Editorial Jus, I959), 86-88.

23. Francisco Montes González, Sevilla guadalupana. Arte, Historia y devoción (Sevilla: Diputación de Sevilla, 2015), 273, 276 y 283.

24. María Concepción García Sáiz y Juan Miguel Serrera, "Aportaciones al catálogo de enconchados", Cuadernos de Arte Colonial, núm. 6 (1990): 66-70; y Sonia I. Ocaña Ruiz, "Nuevas reflexiones sobre las pinturas incrustadas de concha y el trabajo de Juan y Miguel González", Anales del Instituto de Investigaciones Estéticas XXXV, núm. IO2 (2013): 2. 
también, lo sitúa como uno de los ocho únicos trabajadores de la incrustación en nácar que se tienen documentados.

Fue terciario de la Orden de San Agustín, lo que justifica una producción de temática mayoritariamente sacra — salvo excepciones- y su trabajo constante para distintas órdenes religiosas, destacando la orden franciscana según algunos autores. ${ }^{25} \mathrm{Al}$ mismo tiempo, fue diputado mayor de la cofradía del gremio de pintores de México ya en $1728,{ }^{26}$ lo cual demuestra un reconocimiento en vida que perdió con el tiempo. Hallazgos recientes nos llevan a atribuirle un importante grado de erudición que le permitiría plantear elaboradas y complejas iconografías como la de El misterio de la Inmaculada Concepción o Alegoría de la Jerusalén celeste y la orden franciscana. ${ }^{27}$

Además, trabajó como valuador de obras de arte en distintas ocasiones, conociéndosele el aprecio de los cuadros de importantes personalidades del mundo del arte (en 1722, del maestro tirador de oro Pedro Palacios), militar (en 1726, del capitán Nicolás de Eguiara y Eguren) y de la nobleza (en I729, los de don Gaspar Madrazo de Escalera, montero de Cámara del marqués del Valle de la Colina). ${ }^{28}$

Su posición lo vincularía con otros pintores mexicanos del momento. Se le ha relacionado con Antonio de Torres, Miguel Cabrera, los hermanos Rodríguez Juárez o Juan Correa. ${ }^{29}$ Parece existir un determinado vínculo con el círculo familiar de este último, que se reforzaría de confirmarse que él es aquel Pedro Calderón citado en distintos documentos notariales de dicho entorno. ${ }^{30}$ Con Antonio de Torres, por su parte, se sabe trabajó conjuntamente en algún aprecio de pintura (1722) y se han llegado a establecer también vínculos estilísticos. ${ }^{31}$

El juicio estético a su producción ha estado marcado hasta tiempos recientes por los primeros estudios que clasificaron su obra de escasa relevancia y mediano mérito. ${ }^{32}$ Sin embargo, atendiendo a la obra que poco a poco se va cono-

25. Hernández Soubervielle, "El celo espiritual", 342.

26. Elisa Vargaslugo y Gustavo Curiel, Juan Correa. Su vida y su obra. Cuerpo de documentos, t. III (Ciudad de México: Universidad Nacional Autónoma de México-Instituto de Investigaciones Estéticas, 1991), I85.

27. Hernández Soubervielle, "El celo espiritual", 337-354.

28. Toussaint, Pintura colonial, I5O-I52.

29. Hernández Soubervielle, "El celo espiritual", 342.

30. Vargaslugo y Curiel, Juan Correa, I28, I31 y I36.

31. Montes González, Sevilla guadalupana, 2I3-2I4.

32. José Bernardo Couto, Diálogo sobre la historia de la pintura en México, ed. crítica, Manuel Toussaint (Ciudad de México: Fondo de Cultura Económica, 1947), 77. 
ciendo, se descubren creaciones que se caracterizan por su apego a la tradición del siglo xvII, empleando composiciones equilibradas que habitualmente incluyen en segundos planos escenas secundarias o anecdóticas, ${ }^{33}$ tal como ocurre en el lienzo de los patronos de Málaga en San Cristóbal de las Casas. La precisión de su dibujo, el dominio del color y la armonía de las formas serían otras características generales de una obra que, además, presenta rasgos propios de marcada personalidad. Entre los últimos, se ha señalado un particular alargamiento de las figuras y el empleo de unos rasgos faciales muy particulares que afean los rostros. ${ }^{34}$

Pero será la frecuente presencia de unas cartelas de gran tamaño, el elemento que más va a caracterizar su obra, incluyendo algún texto y numeración que complementa y facilita la interpretación de las imágenes. La inclusión de estos elementos es relativamente frecuente en la pintura barroca novohispana, destacando en la producción de Miguel Correa, Ambrosio de Avellaneda o Juan Antonio Arriaga, entre otros. ${ }^{35}$ Pero en pocos casos alcanza las dimensiones y relevancia que les confiere Pedro López Calderón. Sirva de ejemplo el lienzo de los mártires hispano-romanos, según se analizará a continuación, o el muy parecido caso de la Virgen de Guadalupe del exconvento del Carmen en Sanlúcar la Mayor (Sevilla), fechada en I725, que numera e identifica distintos enclaves de referencia en torno al santuario del Tepeyac.

Al considerar estas cuestiones y una vez presentado el autor y su obra, propongo que la mejor manera de abordar el estudio pormenorizado de este lienzo será a partir del texto recogido en la cartela. Con ello, atenderé además a las propias referencias que Pedro López Calderón da para la interpretación y lectura general de la obra en sus distintas escenas.

El texto, escrito en el castellano de la época y aplicando el sistema de abreviaturas normalizado en el momento, podría transcribirse - y respetando su uso de mayúsculas- como:

"San Ciriaco y Santa Paula Virgen, Mártires naturales y Patronos de la Nobilísima ciudad de Málaga, en la Andalucía.

Muralla de dicha Ciudad

Puente del río de Alguamedina

33. García Sáiz y Serrera, "Aportaciones", 66-70.

34. Montes González, Sevilla guadalupana, 214.

35. Montes González, Sevilla guadalupana, 215. 
6. Pedro López Calderón, San Ciriaco y santa Paula (detalle de la cartela). Foto: José Ignacio Mayorga Chamorro. Secretaría de Cultura.INAH. Méx.- "Reproducción autorizada por el Instituto Nacional de Antropología e Historia”.

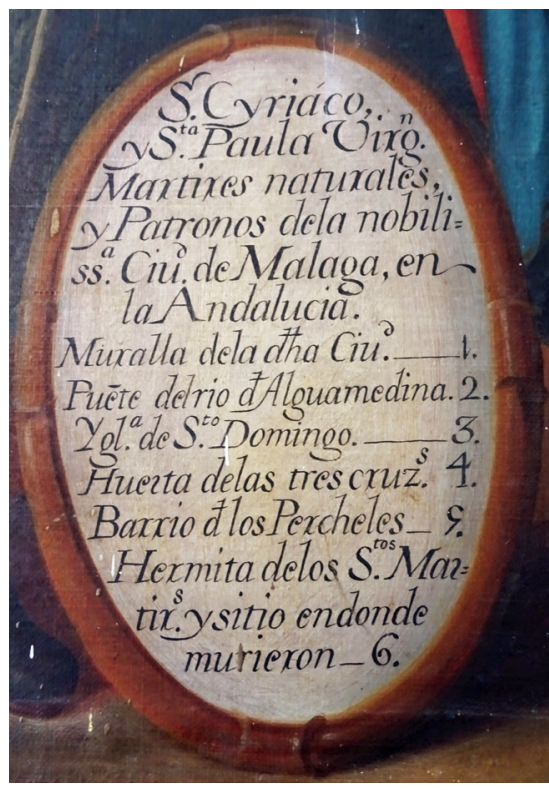

$\begin{array}{lr}\text { Iglesia de Santo Domingo } & 3 \\ \text { Huerta de las Tres Cruces } & 4 \\ \text { Barrio de los Percheles } & 5 \\ \text { Ermita de los Santos Mártires y sitio en donde murieron } & 6 \text { " }\end{array}$

La primera referencia es, pues, a los propios mártires Ciriaco y Paula, a los que se dedica el lienzo (fig. 6). Presentarlos resulta complejo, puesto que su vida e historia - conocidas sobre todo a través de la tradición malagueña- presentan un gran número de variaciones como es propio de un relato popular y carente de fuentes históricas claras que lo sostengan con certezas. Pedro López Calderón parece sumarse a la versión que ya en su época — y hoy día — resulta mayoritaria, la cual los tiene por dos jóvenes cristianos nacidos y muertos en la Málaga romana por causa de su fe. Su origen es incierto y muy discutido, en especial por estudiosos del siglo XIX que, retomando algunos textos medievales, los tienen por oriundos de Cartago Nova (actual Cartagena española) o de alguna ciudad del norte romanizado de África, llegando incluso a negárseles vínculo alguno con Málaga. Pero en el siglo XviII no existía ningún debate 
a este respecto, asimilándolos sin mediación de dudas a la ciudad andaluza de la que son patronos, como hace el pintor.

Ambos "Martiricos" — apelativo popular alusivo a su juventud — serían hermanos según muchas versiones, o bien compañeros de predicación. Pero nunca pareja, siendo Paula virgen, como aquí también se expresa. Vivieron su fe en el ámbito de una primitiva comunidad cristiana malagueńa, probablemente la organizada en torno a san Patricio, primer obispo de Málaga. ${ }^{36}$ Por tanto, su vida discurrió hacia finales del siglo iII y principios del siglo IV, y fueron martirizados en el contexto de la cruenta persecución de Diocleciano, aunque algunos autores los sitúen en el siglo I, discípulos de san Torcuato y muertos por Nerón. ${ }^{37}$ En cualquier caso, cuando se publicara el edicto persecutorio, los dos jóvenes se presentaron ante el magistrado, confesando su fe y negándose a adorar a los dioses de Roma. Éste los mandó atormentar para hacerles cambiar de pensamiento, pero ambos resistieron con entereza los duros castigos. Entonces fueron condenados a morir apedreados, atados a unos árboles o palmeras, junto al cauce del río de la ciudad. Ciriaco y Paula acogieron su muerte con la dignidad y confianza de quienes conocen la gloria de su fidelidad en el martirio. Una vez abatidos, el pueblo quiso quemar sus cuerpos, pero una repentina lluvia providencial los dispersó y ellos quedaron abandonados a la intemperie. Esa misma noche y a escondidas, algún cristiano les dio sepultura en un lugar cercano pero desconocido, no habiéndose localizado sus restos desde entonces..$^{38}$

Ésta es la tradición que, con más o menos exactitud, debió llegarle al pintor de este lienzo, según lo que está representado en el mismo. Son muchos los interrogantes que se nos plantean al respecto y a los que intentaré ir dando respuesta, pero comenzaré por analizar brevemente los orígenes de la propia leyenda para una mejor comprensión de la misma.

Un reciente volumen monográfico dedicado a san Ciriaco y santa Paula $\mathrm{a}^{39}$ ha abordado en profundidad este ${ }^{40} \mathrm{y}$ otros asuntos relacionados con tan

36. Marion Reder Gadow, coord., Los Patronos de Málaga san Ciriaco y santa Paula (Málaga: Real y Piadosa Congregación de los Santos Patronos de Málaga Ciriaco y Paula, 2015), 57.

37. Pedro Morejón, Historia general, y politica de los santos, antigüedades y grandezas, de la ciudad de Málaga, compuesta por el padre Pedro Morejón de la Compañia de Jesús (Málaga: Ayuntamiento de Málaga y Real Academia de Bellas Artes de San Telmo, I999 [ms. ca.I676]), I45-I46.

38. Reder Gadow, Los Patronos de Málaga, 36-37.

39. Véase n. 36.

40. Alberto Jesús Palomo Cruz, "La forja de una leyenda", en Reder Gadow, Los Patronos de Málaga, 25-55. 
cuestionados personajes. Al remitir a estos estudios, que tomo como base para las siguientes páginas, expondré como primer hecho importante la ausencia de documentos de época cercana a la suya que les hagan referencia, aunque debieron existir las actas de su martirio. Por ello el primer grupo de fuentes documentales que se pueden considerar serán los martirologios y calendarios que, desde la época medieval, les comienzan a hacer mención..$^{4 \mathrm{~T}}$ Estos libros de carácter compilatorio, ampliamente difundidos en los distintos territorios de la Iglesia católica, presentan un contenido muy básico. En el caso de Ciriaco y Paula, por lo común, se limitan a recoger la fecha de su onomástica —el i8 de junio- y que murieron lapidados por los romanos a causa de su fe. Sobre el lugar de su muerte, se apuntan distintas versiones según lo ya señalado. Así, el Calendario de Recemundo, del siglo X, los da por cartagineses, ${ }^{42}$ mientras que un martirologio del monasterio de San Pedro de Cardeña, del 919 d.C. — hoy en el Museo Británico-, los tiene por caídos en la africana Tremeta. ${ }^{43}$ Pero con ello, no deja de ser Málaga el escenario más frecuentemente citado. De este modo, el Martirologio de Usuardo (compilación de un monje benedictino francés en el siglo ix d.C., fundamental por su aportación al conocimiento de los primeros santos y mártires hispanos antes de la invasión musulmana), ${ }^{44}$ que quizá sea la más antigua y relevante de estas fuentes, indica: "En España, en la ciudad de Málaga, murieron en este día los señores mártires Ciriaco y Paula, virgen, los cuales de haber padecido muchos tormentos fueron apedreados y dieron sus almas al cielo entre las mismas piedras". 45

A esta vinculación geográfica se suma el peso de la propia tradición y devoción malagueña, pues san Ciriaco y santa Paula sólo recibían culto en dicho municipio y no ostentan más patronazgo que el de esta ciudad, que a su vez es el único lugar donde cuentan con una tradición iconográfica propia.

En algunas de estas fuentes, así como en otros escritos, Ciriaco aparece referido también como Siriaco, hecho que - interpretado como "natural de Siria" - ha reforzado teorías que le otorgan un origen africano u orien-

41. Consultar el listado pormenorizado de estas fuentes en: Reder Gadow, Los Patronos de Málaga, 59 .

42. José Luis Repetto Betes, "Santos Ciriaco y Paula. Mártires, Patronos de Málaga”, en Repetto Betes, coord., Nuevo año cristiano (Madrid: Biblioteca de Autores Cristianos, 200I), 377.

43. Repetto Betes, "Santos Ciriaco y Paula", 377.

44. Reder Gadow, Los Patronos de Málaga, 38-40.

45. Usuardo, Vsuardi Martyrologium quo Romana Ecclesia ac permultae aliae vtuntur: iussu Caroli Magni conscriptum [...] (Amberes: Philippum Nutium, 1583), 85. 
tal. ${ }^{6}$ Sin embargo, tanto esta etimología como la que lo tiene por romanización del griego Kyriacos - "servidor del Señor"-, podrían haberse dado en la Malaca del momento: municipio romano (Municipium Flavium Malacitanum) pero de fundación fenicia y documentada actividad comercial con el mediterráneo oriental.

En cualquier caso, y pese a sus limitaciones, se debe en buena medida a estos martirologios la preservación de la memoria de estos santos mártires. Pues si su culto y recuerdo permaneció entre las primeras comunidades cristianas, más tarde desapareció por completo durante los años de dominación musulmana de la Península Ibérica. Esta etapa, en el caso de Málaga, se prolongó desde la primera mitad del siglo viII hasta el I3 de agosto de I487, cuando los Reyes Católicos conquistaron la Malaqa nazarí en su avance hacia la ciudad de Granada, finalmente tomada en I492.

Es de hecho en el ambiente político, cultural y religioso de esta campaña militar conocida como la Reconquista donde se enmarca la recuperación del culto a san Ciriaco y santa Paula. Según relató el cronista Lorenzo de Padilla, ${ }^{47}$ los Reyes Católicos tuvieron conocimiento de la existencia de estos santos mártires oriundos de Málaga poco después de conquistarla. Fue por medio del papa Inocencio VIII, quien les informara a este respecto tras recibir la embajada de los reyes hispanos comunicándole la toma del enclave junto al ofrecimiento simbólico de Ioo moros allí apresados. El pontífice habría extraído dicha información de algún martirologio conservado en el Vaticano, muy probablemente el ya citado de Usuardo..$^{8}$

Los Reyes Católicos, al recibir la noticia, los nombraron de inmediato patronos de la ciudad cuya recuperación para el cristianismo habrían favorecido con su intercesión. San Ciriaco y santa Paula se convirtieron así en los más antiguos ostentadores de este patrocinio, al que más tarde se sumarían el Santísimo Cristo de la Salud (I649) y la Virgen de la Victoria (I867). Como tales patronos se les presenta en el lienzo de Pedro López Calderón, según cita la inscripción y plantea la imagen pintada.

Los mismos monarcas, además, vinculándolos de nuevo con la protección de la ciudad, les situaron también en las armas heráldicas que le concedieron en 1494 de la forma que sigue:

46. Lisardo Guede y Fernández, Martirologio malaginense (Málaga: 1998), I4.

47. Lorenzo de Padilla, Catálogo de Santos de España (Toledo: 1538) fol. XXI.

48. Véase n. 45 . 
Don Fernando y Doña Isabel [...] acatando de cómo la dicha ciudad de Málaga por gracia de Dios fue ganada por conquista, [...] le damos por armas la forma de la misma ciudad y fortaleza de Gibralfaro con el corral de los cautivos en un campo colorado. Por reverencia de los bienaventurados mártires san Ciriaco y santa Paula, que en la dicha ciudad fueron martirizados, mandamos poner su imagen de cada uno de ellos en par de las torres de Gibralfaro.[...].49

También consagrarían a su culto una de las cuatros parroquias con las que se dotó a la urbe tras su conquista, ya en I488. Desde entonces, el de los Mártires es uno de los templos con mayor relevancia social, histórica y artística de la ciudad y uno de los enclaves destacados en el culto a Ciriaco y Paula, sede de su cofradía y custodia de unas de sus representaciones más veneradas, que presiden desde su propio camarín la actual construcción barroca. ${ }^{50}$

No obstante, el templo que siempre albergó y aún conserva las más numerosas y destacadas representaciones de estos santos fue la catedral malagueña. ${ }^{51}$ Este hecho refleja una realidad esencial para entender la difusión del culto local a san Ciriaco y santa Paula, que es su apoyo y promoción por parte del cabildo catedralicio y del gobierno civil de la ciudad, prácticamente constantes durante la Edad Moderna. Su conocimiento y devoción fueron impulsados por parte de estos organismos de poder con una finalidad de evidentes connotaciones de legitimación religiosa y política propias de su contexto histórico: resaltar el pasado cristiano de la ciudad, reinstaurado tras casi ocho siglos de dominio musulmán.

Así, desde 1507, las autoridades municipales se encargaron de organizar populares fiestas cada I8 de junio, sumándosele décadas después a su apoyo el cabildo eclesiástico. El evento principal era una solemne procesión que discurría entre el ayuntamiento, la catedral y la parroquia de la que eran titulares. En ellas se sacaron en andas, desde i604, unas magníficas esculturas en plata armada sobre madera, encargo municipal al platero local Juan Bautista

49. Cecilio García de la Leńa, Conversaciones históricas malagueñas, tomo III (Málaga: Impr. Luis de Carreras, I789-I793), 220-221.

50. Francisco José Rodríguez Marín, "Arquitectura y devoción. El espacio cultural dedicado a los Santos Patronos", en Reder Gadow, Los Patronos de Málaga, 9I-II3.

5I. José Luis Romero Torres, "La iconografía de san Ciriaco y santa Paula en el arte malagueño", en Juan Aranda Doncel y Julián Hurtado de Molina Delgado, San Rafael y el patronazgo de los santos mártires en Andalucía (Córdoba: Hermandad de San Rafael, 2016), I34-139. 
Barba, que se perdieron durante la invasión de las tropas napoleónicas hacia I8IO. 52

Desde mediados del siglo xvi el culto y la devoción a los santos patronos estaban ya, pues, bien asentados y difundidos entre las clases populares de la ciudad, gozando de bastante aceptación social durante toda la Edad Moderna. Pero fueron el siglo xviı y las primeras décadas del xviII sus momentos de mayor esplendor, coincidiendo además con el fomento de la devoción a los santos y mártires promovido por la Iglesia contrarreformista. De ahí que el mayor número de reproducciones que se conservan de los mártires malacitanos sean obras de este ámbito temporal, como el lienzo de Pedro López Calderón.

Las representaciones de san Ciriaco y santa Paula ${ }^{53}$ eran hasta la fecha, por su reducido culto local, un fenómeno casi exclusivamente malagueño. De ahí lo excepcional del hallazgo en México de este cuadro novohispano, como primer ejemplo de su difusión más allá del municipio del que son patronos y su provincia. Al igual infrecuente resulta su representación por un artista extranjero fuera del ámbito malagueño. Tan sólo existirían unas mínimas referencias previas ilustradas en algunos de los citados martirologios, pero son imágenes genéricas de un martirio por lapidación que en ningún caso hacen referencia a la tradición local como aquí es el caso.

Quizá por ello se trata de una representación de Ciriaco y Paula que, salvo en su cronología, se aleja bastante de las convenciones del arte malagueño. Se nota ya atendiendo a su propio carácter material, dado que estos mártires fueron representados con más frecuencia en esculturas que en pinturas, sobre todo durante los siglos XVII y XVIII.

Aunque el patrimonio sacro malagueño ha sufrido numerosísimas pérdidas debidas a diferentes acontecimientos históricos de la Edad Contemporánea, lo conocido a través de fuentes históricas y lo conservado permite afirmar que las representaciones pictóricas de estos santos mártires son, por lo general, más escasas y de menor calidad que las escultóricas. Así, sólo es posible señalar las tablas que Francisco de Ledesma y Jacome de Lobeo pintaron para el Retablo de Santa Bárbara de la catedral de Málaga en I524 como ejemplos con una cali-

52. Marion Reder Gadow, "El culto a los mártires en la modernidad", en Reder Gadow, Los Patronos de Málaga, 25-55.

53. Dos de los estudios iconográficos más completos sobre los santos Ciriaco y Paula se desarrollan en: Romero Torres, "La iconografía", I23-I46 y Francisco José Rodríguez Marín, "Iconografía y representaciones plásticas de los Patronos", en Reder Gadow, Los Patronos de Málaga, II5-I42. 
7. Pedro de Mena, relieves de san Ciriaco y santa Paula en la sillería del coro de la Catedral de Málaga, Málaga, ca. 1658.

Foto: José Ignacio Mayorga Chamorro.

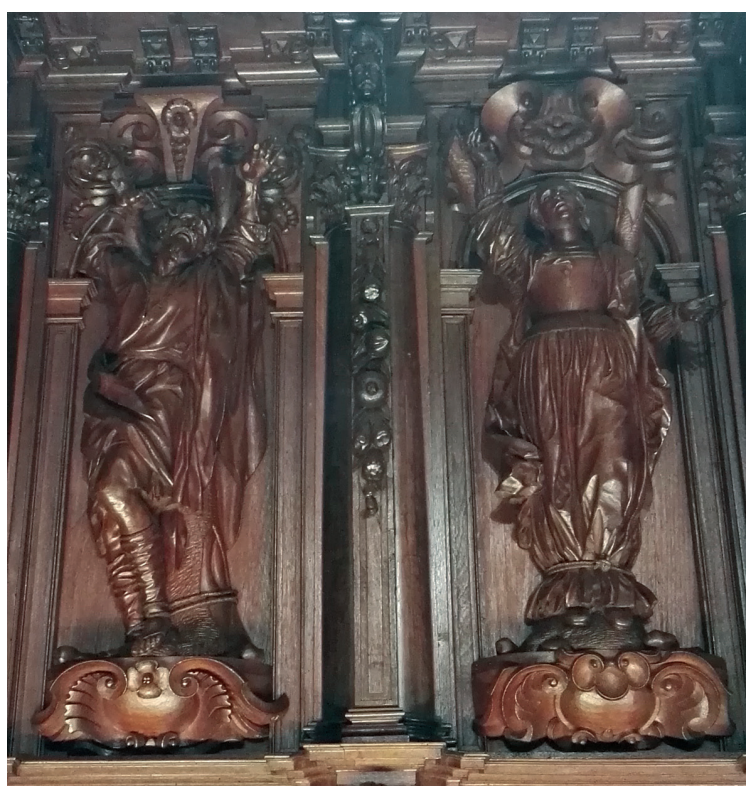

dad equiparable a la obra que ahora descubrimos y analizamos. ${ }^{54}$ En el mismo templo, otros dos lienzos anónimos se incorporaron en I637 como agradecimiento a su protección ante una epidemia sufrida, pero su calidad y estado de conservación son muy deficientes. ${ }^{55}$ En el campo escultórico, mientras tanto, se encuentran creaciones de la talla de los altorrelieves de Pedro de Mena para la sillería del coro de la catedral de Málaga (ca. I660) ${ }^{56}$ (fig. 7) o los medallones marmóreos del portugués Clemente Annes (1730) para las portadas laterales de la fachada principal de dicho templo, ${ }^{57}$ donde también se les esculpe sobre las cornisas del presbiterio en el siglo $\mathrm{XVI}^{58}$ y en la capilla de la Encarnación (Juan

54. Lorenzo Pérez del Campo, "Nicolás Tiller y el retablo de Santa Bárbara en la Catedral de Málaga”, Baetica, núm. 8 (1985): 77-84.

55. Agustín Clavijo García, La pintura de la Catedral de Málaga (Catálogo-inventario) (Málaga: Memoria de Licenciatura inédita-Universidad de Málaga, 1973), 42 y 47.

56. José Luis Romero Torres, "Pedro de Mena, el coro de la catedral de Málaga y algunas fuentes de inspiración", Cuadernos de los Amigos de los Museos de Osuna, núm. I6 (2014): 92-100.

57. Lorenzo Pérez del Campo, Arte y economía: la construcción de la Catedral de Málaga (Málaga: Universidad de Málaga y Colegio de Arquitectos de Málaga, I985), 3 II.

58. Lorenzo Pérez del Campo y José Luis Romero Torres, La Catedral de Málaga (León: Everest, 1986), 20. 
de Salazar, I783).59 Junto a estas representaciones, destacan también otros cuatro grandes relieves anónimos ubicados en el crucero de la parroquia de los Santos Mártires (1770-1777), donde también se encontraban una pareja de esculturas de bulto redondo presidiendo la capilla mayor desde el siglo Xvir. Estas últimas, destruidas en 193I, se sustituyeron por las que Jerónimo Gómez tallara y policromara para el tabernáculo catedralicio entre 1677 y I688. ${ }^{60}$ Además, se sumarían las arriba citadas creaciones en plata y diversas manifestaciones en las artes decorativas y gráficas, así como otros relieves pétreos de corte más popular y menor relevancia distribuidos por el paisaje urbano malagueño. ${ }^{61}$

El número de representaciones es, por tanto, bastante limitado, sobre todo en soporte lienzo, lo que acrecienta de nuevo el valor de este hallazgo. Uno de los motivos argumentados puede ser la importante merma en el patrimonio sacro malagueño derivada de los diferentes procesos de desamortización y de algunos acontecimientos bélicos de la historia contemporánea española, así como de eventos de dimensión local como los acaecidos en mayo de 1931. ${ }^{62}$ Pero no se tiene constancia de que existieran demasiadas obras de relevancia relacionadas con Ciriaco y Paula que pudieran haber llegado a desaparecer, salvo las anteriormente referidas. Con ello, asumo que no hubo un excesivo apego popular al culto de estos santos patronos, más allá de las festividades de promoción oficial, y en consecuencia, los encargos privados movidos por la devoción popular fueron algo bastante escaso. De ahí que el lienzo de Pedro López Calderón destaque una vez más como un caso enormemente particular.

Una de las facetas más excepcionales del cuadro de Chiapas será la solución iconográfica que aporta Pedro López Calderón para retratar a los santos y su martirio, alejándose de una tradición plástica malagueña bastante asentada, pero que él quizá desconocía. El dato más significativo es la representación triplicada de los mismos, contando en un mismo lienzo con su presentación triunfal —ya como santos y mártires- que ocupa el primer plano de la composición, más dos representaciones menores en segundo y tercer término con su lapidación y con su juicio previo.

Comienzo por analizar la primera de ellas refiriendo a su carácter dual, ya que Ciriaco y Paula —él, a la izquierda y ella a la derecha — se representan

59. Romero Torres, "La iconografía", I37-I39 y I45.

60. Reder Gadow, Los Patronos de Málaga, I24-I25.

61. Reder Gadow, Los Patronos de Málaga, I34-136.

62. José Jiménez Guerrero, La quema de conventos en Málaga. Mayo de I93I (Málaga: Arguval, 2006). 
8. Pedro López Calderón, San Ciriaco y santa Paula (detalle de san Ciriaco). Foto: José Ignacio Mayorga

Chamorro. Secretaría de Cultura.-InaH. Méx."Reproducción autorizada por el Instituto Nacional de Antropología e Historia”.

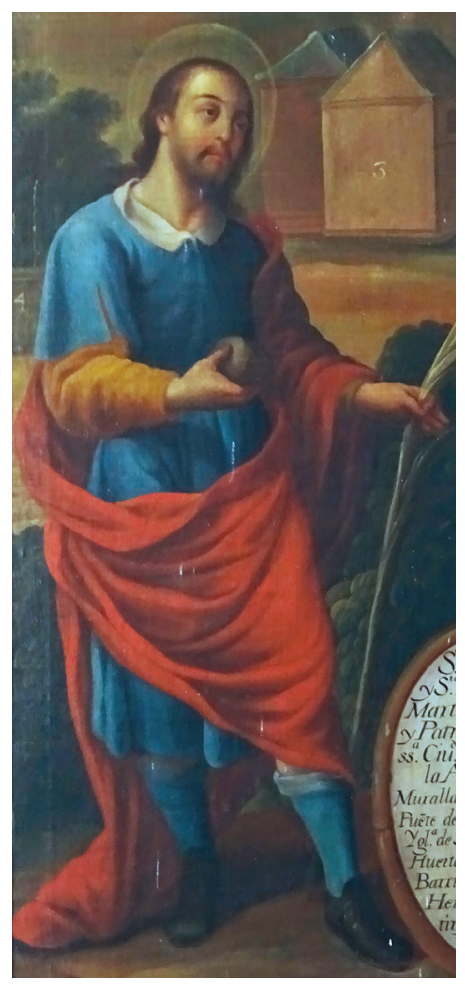

de pie, como pareja y manteniendo unas características comunes. Ambos de corta edad, como dicta la tradición, pero ya adultos y vestidos con ropas contemporáneas a la pintura. Sus túnicas son azules y llevan sendos mantos rojos que caen por sus hombros para aportar, con los pliegues, algo de dinamismo a unas figuras por lo demás bastante estáticas. Él adelanta uno de los pies, en los que lleva zapatos y unas calzas del tono azul de la túnica, cortada a media pierna. El ocre de las mangas y el blanco del cuello aportan los últimos toques de color a una vestimenta de calidad, pero sencilla (fig. 8). Ella, por su parte, presenta un ropaje más rico, adornando con ribetes dorados el escote, el arranque de mangas, la cintura y los bajos de una túnica que se recoge con las manos. El gesto deja ver nuevas capas de la misma tela rosada de sus anchas mangas, bajo las que asoman pliegues translúcidos de seda blanca. Su pelo se presenta descubierto, como mujer virgen, en un elaborado peinado. Y adorna con joyas el escote y orejas, retratándose como a la dama de clase alta que sería según algu- 
nas versiones de la leyenda que, además de hermanos, los tenía por nacidos de buena familia y parientes de importantes centuriones (fig. 9). ${ }^{63}$

Respecto a su posición, los dos se presentan de pie y volteados apenas el uno hacia el otro, hacia el centro de la composición. Allí se encuentran las delgadas palmas, símbolo de su martirio, que sujetan en su mano izquierda él y ella en la derecha, donde vienen a caer los respectivos mantos. Por su parte, el nimbo que confirma su santidad se dibuja en forma sutil tras sus cabezas, también suavemente perfiladas hacia el centro. El santo mira impasible hacia el frente, mientras que la santa eleva los ojos al cielo - hacia el Dios por el que sufrieron la muerte, pero que también les ha dado la gloria-, aportando cierto toque de expresividad que, no obstante, dista mucho de lo propio de una representación barroca.

Hasta aquí, buena parte de lo expuesto corresponde, a grandes rasgos, con lo visto en otras representaciones de Ciriaco y Paula de esta época, por ejemplo, las esculturas que en la actualidad se custodian en la parroquia de los mártires y que codifican la imagen más asimilada en el ideario colectivo (fig. Io). Sin embargo, falta uno de los elementos que quizá les sea más distintivo y característico: el árbol al que suelen aparecer amarrados para propiciar su flagelación. Aunque según algunas de las fuentes más antiguas se trató de una palmera (inexistentes en Málaga, incongruentemente, durante la época romana), lo cierto es que en la gran mayoría de los casos están retratados juntos a árboles de pequeño porte, o más bien sus troncos, reducidos al perfil de las figuras humanas que les preceden.

En cualquier caso, este elemento de inclusión popular (los martirologios no lo citan, hablan sólo de lapidación) tuvo un gran éxito en la plástica malagueña, pues permitía a los artistas subrayar el tormento del martirio con sus ataduras y las forzadas poses que con ellas adquirían. ${ }^{64}$ Es el caso de los relieves de Pedro de Mena o de Clemente Annes en el coro y las portadas de la catedral de Málaga, que ambos aprovecharán para aumentar el dramatismo barroco de la escena.

No obstante, Pedro López Calderón, ajeno a la tradición plástica local, resuelve la plasmación de tal martirio por otras vías. Resalta el instrumento

63. Morejón, Historia general, I45.

64. Carlos Arturo Salamanca Villamizar, "Religión, política y espectáculo: narrativas del martirio en la primera modernidad", Anales del Instituto de Investigaciones Estéticas XXXVIII, núm. Io9 (2016): 97-I33. 
9. Pedro López Calderón, San Ciriaco y santa Paula (detalle de santa Paula). Foto: José Ignacio Mayorga

Chamorro. Secretaría de Cultura.-INAH. Méx."Reproducción autorizada por el Instituto Nacional de Antropología e Historia”.

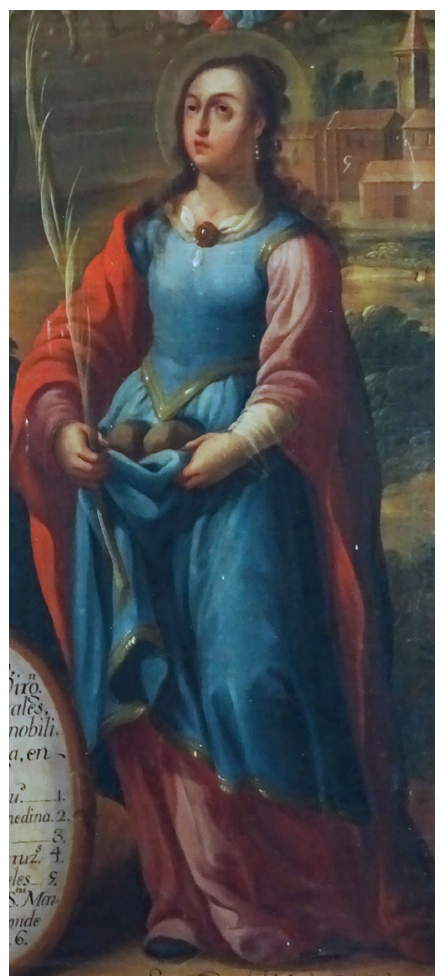

de su lapidación: las piedras, que cargan y muestran los propios santos, cuando, por lo general, se disponen en el suelo en torno a sus figuras. Así, mientras Ciriaco agarra un canto redondeado con la mano derecha, Paula recoge su manto con ambas manos para albergar otros dos, de buen tamaño. Esta interpretación sólo cuenta con un referente conocido: el relieve de santa Paula que desde el siglo Xvi se eleva en el nivel superior de los pilares de la capilla mayor de la catedral malagueńa. Pero muy difícilmente Pedro López Calderón o su informante pudieron conocer esta imagen, poco visitada incluso hoy día por su difícil visualización.

Alrededor de las figuras, en el lienzo, no se localizan más piedras, pues en este primer término no se representa su martirio ni el escenario de su lapidación, sino a Ciriaco y Paula como santos, mártires y patronos de la ciudad de Málaga, como los presenta la inscripción. Así, Pedro López Calderón, alejándose del dramatismo propio de otras representaciones barrocas que resaltan el 
momento de su ejecución, relega esta escena a un segundo plano, destacando la idea de la santidad y del patronato malacitano, que constituye el logro y triunfo de su martirio.

Resulta paradójico que una de las creaciones plásticas que hasta la fecha mejor ha plasmado a unos personajes tan locales y a los elementos que los definen — su martirio y su patronato — haya sido producida fuera de Málaga y de la Espańa peninsular, obra de un pintor novohispano y por completo ajeno a su tradición iconográfica.

Esto último se puede afirmar tras descartar, casi con toda seguridad, la existencia de algún grabado que pudiera haber tenido el pintor como referencia, siendo ésta una frecuente vía de migración iconográfica en el Atlántico. Las representaciones gráficas que se conocen de Ciriaco y Paula anteriores a 1716 son muy escasas, a menudo sencillas, y no responden nunca a la propuesta que se analiza en este lienzo. El grabado anónimo con el Escudo de la ciudad de Málaga con san Ciriaco y santa Paula que incorpora la portada del libro del padre Martín de Roa, ${ }^{65}$ impreso en I622, es muestra de ello y la única referencia datada con certeza como anterior al lienzo. Del siglo xviII, pero fecha y autoría indefinidas, es el Aleluya (fig. II) con la imagen de los santos producida por la catedral malagueńa, que posee cierto parecido con el cuadro novohispano en la disposición básica de los santos con la ciudad de fondo, pero que se mantiene fiel a la tradición iconográfica malagueńa al presentarlos atados al árbol y rodeados de piedras ${ }^{66}$ Además, el paisaje urbano que presenta como fondo es genérico y no se localizan los elementos específicos del enclave malagueño que sí incorpora el lienzo, siendo todos ellos motivos más que suficientes, en su conjunto, para descartar su posible uso o referencia por López Calderón.

Tras presentar a los santos textual y gráficamente como patronos de la ciudad, analizaré la obra con base en lo recogido en la cartela — como hasta ahora-, atendiendo en este caso a los últimos detalles de su encabezado, que según recordamos cita: "San Ciriaco y santa Paula Virgen, mártires naturales y patronos de la nobilísima ciudad de Málaga, en la Andalucía.". La referencia a la "nobilísima" ciudad de Málaga responde al título de "muy noble" que le fue concedido ya en 1492 y que aun hoy se suma a otros en su lema. ${ }^{67} \mathrm{La}$ alu-

65. Martín de Roa, Málaga. Su fundación, su antigüedad eclesiástica i seglar (I622) (Málaga: El Guadalhorce, 1960).

66. Romero Torres, "La iconografía", I46.

67. Daniel Sedeño Ferrer, "Escudo de armas de la ciudad de Málaga", Baetica: Estudios de Arte, Geografía e historia, núm. 22 (2000): 359-372. 


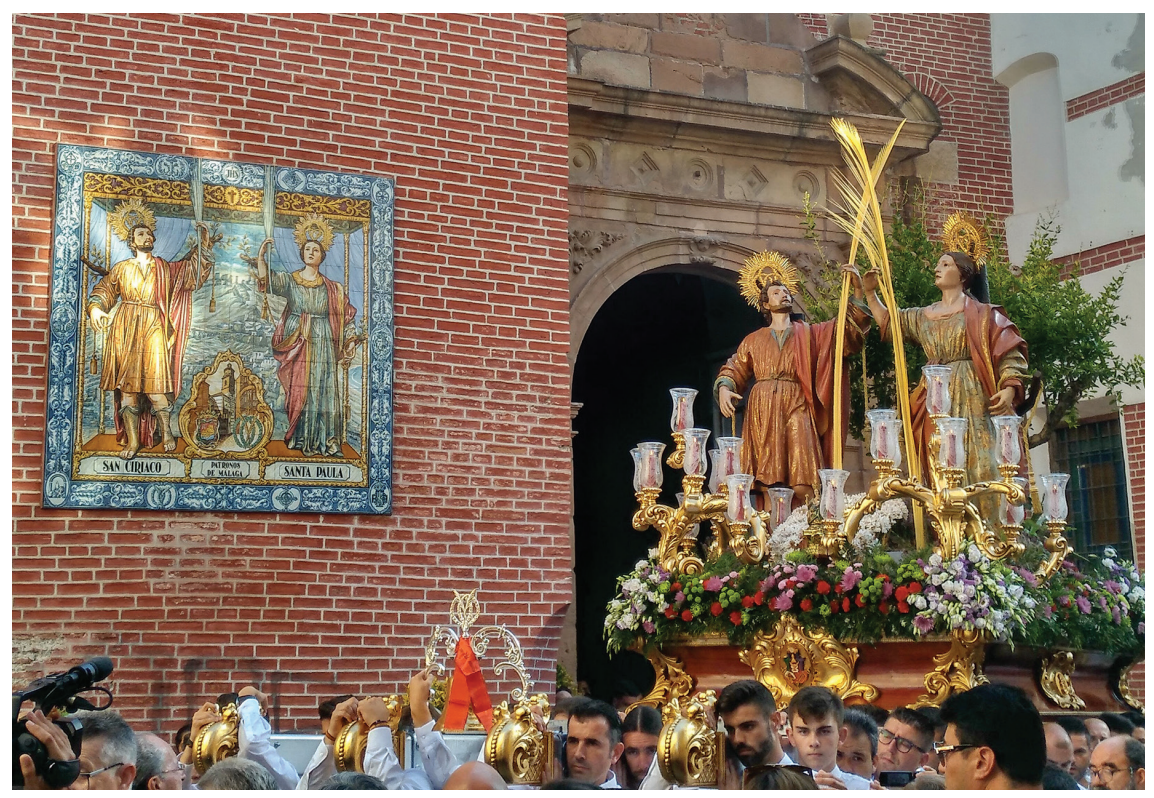

Io. Jerónimo Gómez, San Ciriaco y santa Paula (detalle en salida procesional desde la Parroquia de los Santos Mártires el I8 de junio de 2017), 1677, Málaga. Foto: José Manuel Leiva Aldea.

sión a la región de España de la que forma parte queda justificada por la posibilidad de que su ubicación no fuese conocida entre el público novohispano que contemplara la pieza. Y además, evita posibles confusiones con cualquiera de las 18 otras localidades menores que llevan el nombre de esta ciudad por distintas regiones del mundo, incluyendo varias en territorios estadounidenses antes novohispanos, y una aún en el estado mexicano de Durango. ${ }^{68}$

$\mathrm{Al}$ atender a la representación plástica de la ciudad, se observa cómo ésta se sitúa en el plano más lejano de la composición, rodeada de una muralla y junto al cauce del río, que cruza en forma transversal el paisaje. Con este recurso, el pintor separa dos escenas secundarias que ilustran dos momentos relevantes del martirio de los santos, que acontecen de manera simultánea en sendos márgenes del río. De tal modo que es posible identificar tres grandes franjas horizontales de parecido tamańo como esquema rector de toda la composición: la

68. Pedro Luis Gómez, "2I Málagas por el mundo", consultado el II de diciembre de 20I7, en http://www.diariosur.es/v/20I21007/malaga/malagas-mundo-20I21007.html. 


\section{JOSÉ IGNACIO MAYORGA CHAMORRO}

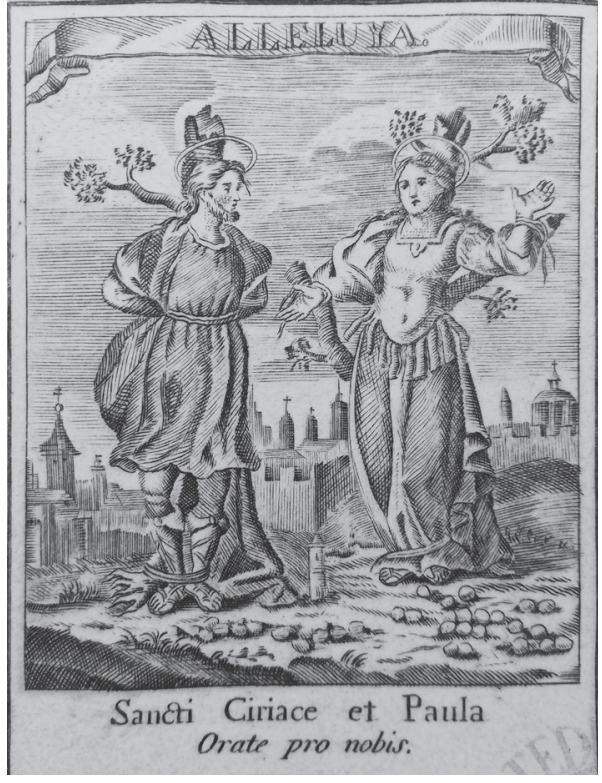

II. Anónimo, Aleluya con san Ciriaco y santa Paula, siglo XviII, grabado, Málaga. Archivo catedralicio.

superior con la vista de la ciudad y el juicio; la intermedia con la lapidación, del lado derecho, junto a una serie de edificios y enclaves propios de este paisaje periurbano, a los que identifica la leyenda; y el primer plano con los santos y la cartela que presenta y explica el conjunto.

La composición es por tanto sencilla y emplea recursos habituales de la plástica de su época. En este caso, destaca en particular la inverosímil coexistencia en un mismo espacio y tiempo - aunque secuenciados en distintos planos- de unos mismos personajes que se repiten por triplicado. Un recurso narrativo con el que se trata de transmitir al fiel los momentos más importantes del relato hagiográfico representado, y que empezamos a descubrir como habitual en la obra de Pedro López Calderón. Así, se emplea de manera similar en obras que ejecuta después, como una santa María Egipciaca de I72I en colección particular ${ }^{69}$ o el san Juan Nepomuceno de 1723, custodiado en el Museo de Guadalupe en Zacatecas, en el que repite además la inclusión de cartelas.

69. "Santa María Egipciaca", consultado el 4 de enero de 20r8, en https://www.setdart.com/ subasta/popup/cat=26/pintura-de-alta-época/pid=350818594.html. 
Sin embargo, lo verdaderamente esencial y misterioso en esta parte del lienzo no es tanto cómo se representan sus distintos elementos, sino cuáles de ellos —edificios, huertos y poblados_ son los representados. En especial si se tiene en cuenta que Pedro López Calderón, aunque no pudo conocerlos de primera mano ni reproducirlos por tanto de manera certera, parece querer asegurarse de su correcta identificación recurriendo a su referenciación numerada. El marcado carácter didáctico de este recurso se justifica plenamente considerando que el lienzo se concibió en un contexto en el que los personajes y escenarios representados serían por lo general desconocidos.

En algunos casos, la inclusión de determinados elementos es lógica y deriva de su vínculo con la vida y muerte de los santos, pero en otros sus motivos resultan menos evidentes, como expondré a continuación. Inicio así un recorrido detallado por cada una de las citadas referencias, siguiendo la numeración que les atribuye la cartela, pero alterando el orden de su aparición a fin de alcanzar una mayor coherencia con el relato hagiográfico, inexplicablemente confuso en la secuencia original por la inclusión de elementos poco justificados, según se verá.

\section{Muralla de la dicha ciudad}

La primera referencia numerada que recoge la cartela es a la muralla de la ciudad. No es un elemento tan relevante en la leyenda de Ciriaco y Paula, salvo por el hecho de que su lapidación suela ubicarse fuera de su recinto. La ciudad de Málaga, por su carácter costero, contó con una importante dotación defensiva que se remonta a las primeras murallas fenicias, ampliadas en época romana y sobre todo durante los siglos de dominio musulmán. ${ }^{70} \mathrm{Su}$ trazado final fue de perfil almendrado, circunvalando la ciudad, y a lo largo del mismo se sucedían distintas torres, con un aspecto que dista mucho de la muralla cuadrada y de lienzos corridos que recrea López Calderón.

La Málaga ahí representada vendría a responder a aquello que un pintor novohispano entendería como imagen genérica de una pequeña ciudad europea. Como tal, está dotada de muralla —elemento menos frecuente en los virreinatos españoles de América, salvo en el Caribe y otras excepciones-, y presenta un paisaje caracterizado por las numerosas y escarpadas agujas y pináculos que culminan sus construcciones. Sin embargo, Málaga, como ciudad mediterránea y musulmana hasta finales del siglo Xv, carecía de este tipo

70. María del Carmen Íńiguez Sánchez, José Antonio Rambla Torralvo y José Francisco Mayorga Mayorga, "La construcción de la muralla musulmana de Málaga, un hito en la historia de la ciudad", Mainake, núm. 25 (2003): 133-176. 
de elementos más propios del mundo medieval y de climas fríos. La Málaga moderna fue una ciudad sobre todo conventual, con un horizonte poblado de campanarios y espadañas, pero alejado del ahí representado. ${ }^{71}$ Además, en su representación se omite el elemento más característico e hito fundamental de su paisaje urbano, presente en sus armas y en cualquiera de las representaciones que a lo largo de los siglos hayan querido retratar la ciudad: el monte Gibralfaro con las dos fortalezas que lo coronan.

Es decir, Pedro López Calderón no quiere retratar en forma fiel la ciudad, sino sólo referirla como escenario de la historia de Ciriaco y Paula, y —en este caso concreto- de su procesamiento judicial. No obstante, lo hace de manera cronológicamente inverosímil, pues recrea unos acontecimientos ocurridos en la Antigüedad romana en una ciudad, ante unos edificios y con unos personajes caracterizados por rasgos propios de la Edad Moderna.

No se sabe con certeza dónde se produjo el juicio a estos mártires, pero se cree que ante un tribunal romano que se localizaría en el centro de la ciudad. No obstante, ahí la escena se ubica a las afueras de la muralla y junto a la puerta de acceso, entendiendo que sólo para permitir su mejor visualización.

Un juicio romano por las causas y en los tiempos del de Ciriaco y Paula, constaría, tras la correspondiente detención y encarcelamiento, de varios interrogatorios ante un magistrado o gobernador, como ahí se representa. En esta escena, las figuras de los protagonistas con facilidad se identifican al aparecer vestidas al igual que en el primer plano, y ocurre lo mismo en la lapidación. Se presentan de pie y custodiados por sendos soldados dotados de casco y coraza, que les agarran los hombros desde las espaldas. Pero la escena carece de violencia y los santos hacen ademanes de dialogar con el magistrado, que los interpela alzando la mano desde el estrado sobre el que preside el juicio o interrogatorio. Esta estructura consta de una plataforma levemente elevada sobre un par de escalones y, a su vez, se cubre con dosel y vistosos cortinajes; todo en un intenso color rojo.

El nombre de este magistrado fue Silvano, según la tradición que Francisco Javier Simonet difundiera con gran arraigo en Málaga hacia i865, y que parte de su estudio del llamado Himnario de Toledo, publicado en 1775 por el arzobispo Francisco Antonio Lorenzana. ${ }^{72}$ Sin embargo, otras versiones de la

7I. Francisco José Rodríguez Marín, Málaga conventual: estudio histórico, artístico y urbanistico de los conventos malagueños (Málaga: Arguval, 2000).

72. Francisco Javier Simonet, Los santos mártires Ciriaco y Paula (Málaga: Francisco Moya, Librero Ed., I865), 26-27. 
leyenda —igualmente carentes de fundamentos históricos— lo llaman Aloso, como hace el jesuita malagueño Pedro Morejón, que también se aparta de la versión mayoritaria al fechar los hechos en 58 d.C. y enmarcarlos en la persecución de Nerón. ${ }^{73}$

En el momento del juicio representado en esta obra, se requeriría a los cristianos que renunciaron a su fe y adorasen a los ídolos romanos, pudiendo ser absueltos si acataban esta orden (misericordia crudelior). Con frecuencia se recurría a diferentes métodos de tortura para propiciar tal resultado, si en primera instancia se resistían a hacerlo, y sólo si tras ello persistía su obstinación, se les dictaría y ejecutaría sentencia de muerte.

Así sucedió con Ciriaco y Paula, que según algunas versiones históricas sufrieron diversos tormentos en su procesamiento, antes de su lapidación. ${ }^{74}$ Pero en ningún caso se especifica cuáles habrían sido, y se carece también de representaciones artísticas que aborden tal episodio, también omitido por López Calderón.

No obstante, su pintura es la representación más antigua que se conoce del juicio a Ciriaco y Paula, siendo el primer artista que se embarca en la recreación de este poco atendido capítulo de su martirio. Hasta su descubrimiento, la primera representación del juicio documentada era uno de los cuatros relieves anónimos dedicados al apresamiento de Ciriaco, apresamiento de Paula, su juicio conjunto y lapidación, que se ubicaron en el crucero de la parroquia malagueña de los Santos Mártires entre 1770 y 1777, cuando ésta se reconstruyó en estilo barroco. ${ }^{75}$

\section{Puente del río de Alguamedina}

Con el número dos se identifica al puente del río Guadalmedina, que aparece referido como Alguamedina en una derivación poco común del original árabe wál al-madina "río de la ciudad", pero que en época de Ciriaco y Paula se llamaba Flavium Federatorum. Este pequeño caudal recorre el lateral oeste de la

73. Morejón, Historia general, I45-I46.

74. Sirva de ejemplo, por su minucioso relato y especial difusión en el ámbito malagueńo, el texto recogido por el Himnario de Toledo a través de Francisco Javier Simonet (Simonet, Los santos mártires, 26-27) que dice: "Lleno de furia el juez, manda herir a golpes los cuerpos sagrados, ejecuta en ellos diversas clases de tormentos; pero no consigue mudar sus corazones creyentes. Al fin bárbaramente heridos los mártires junto a unas palmas, al golpe de las piedras emigran sus almas al templo de las alturas".

75. Romero Torres, "La iconografía", I33. 
ciudad de Málaga para desembocar en el mar junto a la misma, como se representa con acierto en el cuadro novohispano.

La referencia al puente — pequeño y de madera, como los que entonces tenía - no tiene aparente explicación ni conexión con estos mártires, al igual que ocurría en la anterior alusión a la muralla. Pero de nuevo, se puede tomar como una alusión al conjunto, es decir, a todo el río y su paraje, con los que sí existe una importante conexión.

Desde los primeros momentos de la difusión y forja de la leyenda popular en la Málaga reconquistada, se dedujo que la lapidación de sus patronos habría tenido lugar fuera de la ciudad y junto al cauce del Guadalmedina. Quizá, como dice Martín de Roa, por tenerse allí las piedras más a mano y en buen número para proceder al apedreamiento. ${ }^{76}$

La tradición también hace a sus cuerpos enterrados junto al cauce del río, un hecho posible que con el paso del tiempo y la ficción popular se ha ido complementando con diversas anécdotas de corte milagroso, en especial en el siglo xix. Para entonces, se solía comentar que la tormenta providencial desatada con la muerte de los santos provocó una de las devastadoras y frecuentes crecidas del río, que veneró y respetó el lugar donde éstos habían recibido muerte y secreta sepultura, rizándose y replegándose las aguas a su paso. Mientras que a la mañana siguiente el pueblo pagano, al no localizar resto alguno de sus cuerpos, los dio por arrastrados por la corriente y perdidos en el mar. ${ }^{77}$

Incluso se llegó a relatar que, durante las noches, desde la ciudad, se vislumbraban unas misteriosas luces en aquel lugar que señalarían la presencia de los restos de los santos, ${ }^{78}$ en un relato que vendría a conectar su leyenda con el hallazgo de los restos del apóstol Santiago en Compostela. ${ }^{79}$

\section{Ermita de los Santos Mártires y sitio donde murieron (fig. I2)}

Así, en la Málaga de la Edad Moderna existió la creencia colectiva de que los cuerpos de sus santos patronos se encontraban enterrados en algún lugar cer-

76. Roa, Málaga, 66.

77. Benito Vila, Guía del viajero en Málaga (Málaga: La Ilustración Española, I86I), IIO-III y Morejón, Historia general, I5I-I52.

78. Vila, Guía, iıo-ıı y Roa, Málaga, 66.

79. Un estudio pormenorizado de las mismas se puede consultar en Francisco José Rodríguez Marín, "Arquitectura y devoción. El espacio cultural dedicado a los santos Patronos/El solar de la ermita: razones de una elección”, en Reder Gadow, Los Patronos de Málaga, Io6-Io8. 


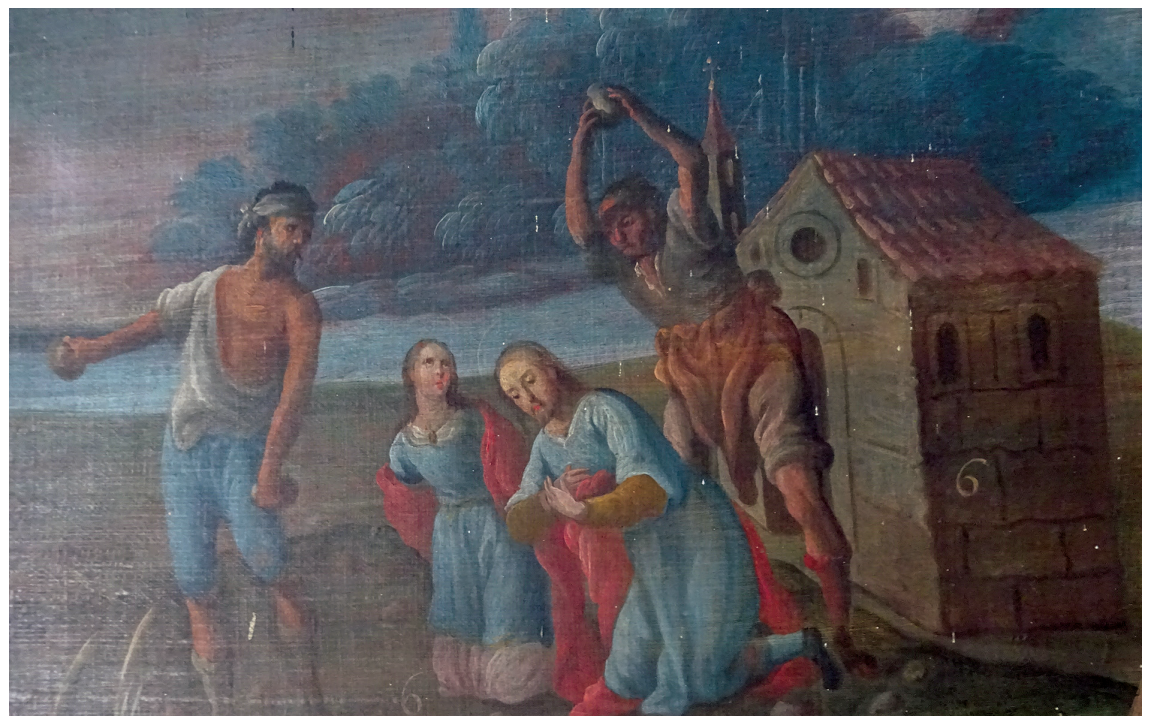

I2. Pedro López Calderón, San Ciriaco y santa Paula (detalle de la lapidación ante la ermita). Foto: José Ignacio Mayorga Chamorro. Secretaría de Cultura.-INAH. Méx.- "Reproducción autorizada por el Instituto Nacional de Antropología e Historia”.

cano al cauce del Guadalmedina, y más en concreto cerca del lugar en el que el Arroyo de los Ángeles se le sumaba y del camino que conducía hacia el convento de los Ángeles. Sin embargo, ninguna de las numerosas campañas de búsqueda consiguió dar con sus restos. ${ }^{80}$ No obstante, la devoción popular movió a la creación de una sencilla ermita que les recordaría en el lugar donde se suponía su muerte, y que desde entonces y aún hoy se conoce como "Martiricos". La primera construcción se levantó en i630 por un particular llamado Cristóbal Ramón, y se encontraba en una finca privada que fue cambiando sucesivas veces de manos. Fue poco a poco dotada de capellanía, tierras y sucesivas mejoras, pero un fuerte terremoto la arrasó en 1680. De inmediato fue reconstruida en el mismo lugar gracias a donaciones de distintos fieles y del entonces obispo, fray Alonso de Santo Tomás. Y el nuevo templo, de mayores dimensiones, se inauguró con gran fiesta popular en I687. Se conoce poco de la

80. Campañas estudiadas en Reder Gadow, Los Patronos de Málaga, 49-50, y testimoniadas por fuentes como Antonio López Guijarro, Novena de los Santos Mártires Ciriaco y Paula (Málaga, I830), 2I. 


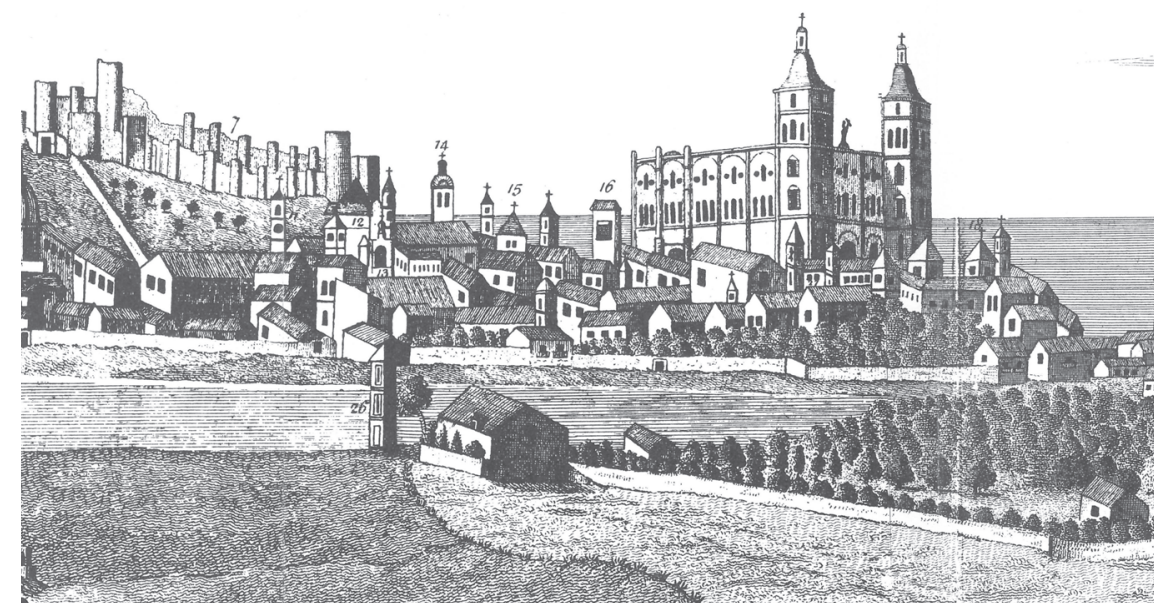

I3. Francis Carter, Vista de Málaga desde una colina al noroeste, en A Journey from Gibraltar to Malaga (detalle de la ermita de Martiricos y la Huerta de las Tres Cruces), vol. II (Londres: Nichols, 1780 [ $2^{\mathrm{a}}$ ed.]), lib. IV, 236.

construcción, que se encontraba en mal estado desde finales del xviII y prácticamente desvalijada y arruinada desde la ocupación napoleónica de principios del XIx. Así que hacia I884, cuando las antiguas huertas se empiezan a urbanizar, el obispado entregó la parcela donde se encontraba la ermita a una fundación religiosa que la demolió para construir un asilo, hoy convertido en colegio. ${ }^{81}$

Su arquitectura puede reconstruirse, no obstante, por su aparición en diversos grabados con vistas de la ciudad realizados en los siglos XVIII y XIX, según ha estudiado el profesor Rodríguez Marín. ${ }^{82}$ Todas ellas, tomadas desde alguna de las suaves colinas que hay por la zona, ofrecen una perspectiva poco frecuente de una Málaga que por lo común ha sido retratada, con su puerto, desde el mar. Curiosamente, este infrecuente punto de vista es el que presenta Pedro López Calderón, quien no obstante no pudo conocer ninguna de estas fuentes gráficas, siendo la más antigua la realizada por Francis Carter en I773 (figs. I3 y I4).

8I. Sobre la historia del edificio, consúltese: Francisco José Rodríguez Marín, "Arquitectura y devoción. El espacio cultural dedicado a los santos Patronos/Ermita de Martiricos-El solar de la ermita: razones de una elección-Arquitectura e iconografía de un edifico desaparecido", en Reder Gadow, Los Patronos de Málaga, IO4-III.

82. Rodríguez Marín, "Arquitectura y devoción", IO4-III. 


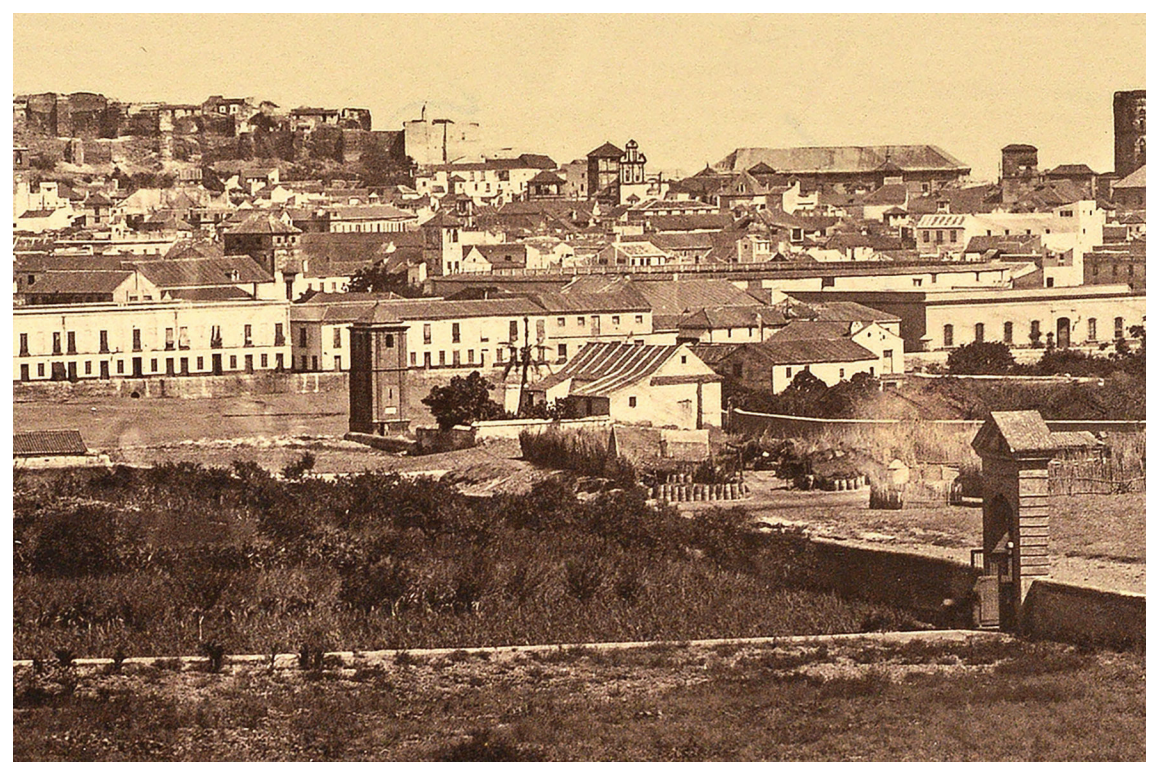

I4. Charles Clifford, Vista de Málaga desde la zona del Arroyo de los Ángeles (detalle de la ermita de Martiricos y la huerta anexa), i859, Málaga. Colección Fernández Rivero.

De I860-1862 es la fotografía más antigua de Málaga, que por casualidad está tomada desde este mismo punto de vista, mostrando aún la presencia de la ermita. El sencillo templo formado por una pequeña nave cubierta a dos aguas que se ve en éste y otros testimonios gráficos bien puede parecerse al que pinta Pedro López Calderón. Al no haber localizado otras representaciones pictóricas de la ermita, al menos con carácter histórico, todo parece indicar que la de este lienzo se trata de la primera y única representación pictórica de este edificio consagrado a Ciriaco y Paula. Como no consta que el autor pudiera conocerlo, salvo por descripciones de terceros, su parecido puede explicarse como una coincidencia, pues la ermita malagueña responde, con su modesta y sencilla arquitectura, a un patrón frecuente para este tipo de edificación en el mundo hispánico, al que Pedro López Calderón simplemente recurriera por conveniencia.

De nuevo, lo importante no es el edificio en sí, sino el acontecimiento ocurrido en aquel lugar, al que en este caso sí se hace referencia directa en la cartela como "sitio donde murieron". Se representa pues la lapidación de los dos 
jóvenes romanos frente a la construcción que tiempo después se levanta para recordar dicho acontecimiento, recurriéndose de nuevo al decidido anacronismo que caracteriza a toda la obra.

Desde el punto de vista iconográfico interesa analizar la manera en la que se recrea el evento, con los dos jóvenes juntos y arrodillados en el instante previo a recibir las pedradas que acabarían con sus vidas. Él junta sus manos en el pecho y baja la cabeza en gesto de resignación y recogimiento. Ella, por su parte, alza el rostro y observa el dramático instante en que un verdugo se dispone a golpear con una piedra a su compañero, al mismo tiempo que, por el lado izquierdo, otro individuo de aspecto plebeyo gira al torso descubierto y eleva el brazo para asestarle un nuevo golpe mortal.

En esta ocasión, y siendo consecuente con la representación principal de los santos en el cuadro, Pedro López Calderón tampoco dispone a los mártires atados a ningún árbol, apartándose del modelo malagueño para presentar una lapidación al uso. ${ }^{83}$ Con ello se ajusta a lo descrito por algunas fuentes, que refieren a estos santos como imitadores en su martirio a san Esteban; protomártir al que se suele representar, precisamente, como en este lienzo. ${ }^{84}$

Esta variante iconográfica menor del martirio de Ciriaco y Paula ya estaba presente en otras obras, ya fuera iluminada en el Martirologio de Usuardo o repujada en plata en el frente de altar de la Capilla del Sagrado Corazón de la catedral de Málaga. ${ }^{85}$ Pero sí que será la primera vez que esté representada como escena secundaria de un conjunto mayor. Hasta I7I6, las representaciones de su martirio se habían centrado exclusivamente en este asunto, pero no ha existido otra obra que combine en una misma composición este acontecimiento con otros pasajes de su historia. Menos aún con dos más, como en este caso: su juicio previo y su posterior triunfo en santidad; un esquema que jamás se ha vuelto a repetir y que habla de la mayor libertad en la no correlación de espacios y tiempos que caracteriza a buena parte de la pintura barroca en Iberoamérica.

83. Romero Torres, "La iconografía”, I30-I34, y Rodríguez Marín, "Iconografía y representaciones plásticas de los Patronos”, en Reder Gadow, Los Patronos de Málaga, II5-I42.

84. Morejón, Historia general, i45 y Roa, Málaga, 65.

85. María Rosa Ferrer, María Josefa Arnall, Milada Studnickova, Joaquín Yarza Luaces y Gabriel Roura, Martirologio de Usuardo (Barcelona: Moleiro, I998 [edición facsímil del códice conservado en el Museu d'Art de Girona y propiedad del Museu Diocesà de Girona, ilustrado $c a$. I400]). 
I5. Pedro López Calderón, San Ciriaco y santa Paula (detalle de la Huerta de las

Tres Cruces). Foto: José Ignacio Mayorga Chamorro. Secretaría de Cultura.-INAH. Méx.-

"Reproducción autorizada por el Instituto

Nacional de Antropología e Historia”.

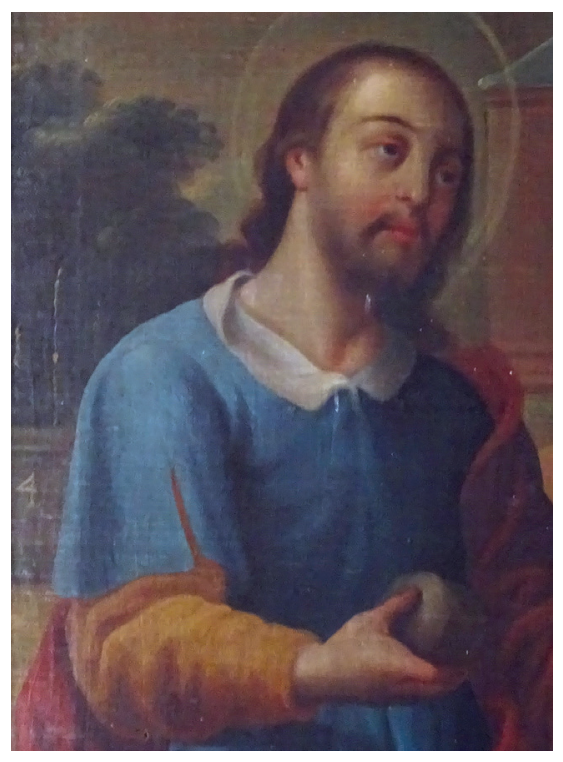

4. Huerta de las Tres Cruces (fig. I5)

Aneja a la ermita de los Mártires se encontraría la Huerta de las Tres Cruces. Su nombre le viene dado por el triple crucero de piedra que existía frente al pequeño templo, al inicio del camino que, paralelo al río y a esta finca, conducía hasta otra ermita: la de la Aurora. ${ }^{86}$ No obstante, anteriormente se la conocía por Perdida y con posterioridad se llamó de Natera, ${ }^{87}$ siendo así como suele aparecer referida en la cartografía desde el siglo XviII hasta su urbanización. El historiador Medina Conde la refiere también como de Martiricos, por razones evidentes, aunque hoy día suela identificarse con dicho nombre al área de la huerta colindante, situada en la otra margen del Arroyo de los Ángeles. ${ }^{88}$

Su inclusión en el lienzo queda justificada por el hecho de que la ermita fue promovida, dotada y mantenida a lo largo de la historia por los distintos dueños de la propia finca, dentro de cuyos terrenos se contaba pese a quedar fuera

86. Manuel Muñoz Martín, "Contribución al conocimiento de la historia de los espacios utilizados para el crecimiento superficial de la ciudad de Málaga durante el siglo xix” (tesis doctoral, Universidad de Málaga, 2003), 340.

87. Reder Gadow, Los Patronos de Málaga, io4 y iıo.

88. Manuel Muñoz Martín, "Importancia del antiguo entorno huertano en la expansión urbanística de nuestra ciudad”, Jábega, núm. 63 (1989): 43-44. 
de sus muros. No obstante, su uso no era privado sino público, y se registraron también aportaciones del obispado y de otros particulares, en especial para su reconstrucción. ${ }^{89}$

$\mathrm{Al}$ retomar la fotografía y las litografías del XIx en las que antes se veía la ermita, también se observa, aneja a ésta, la alta tapia que la cerca. E incluso un acceso de porte clásico que, con su monumentalidad, hablaría de la relevancia de una finca que estaba dotada de casa, tejar, arboleda y hornos.

Lo anómalo es que, en el cuadro de López Calderón, huerta y ermita aparezcan separadas. Así, curiosamente, mientras que el conjunto de referencias que incluye la composición se encuentran localizadas de manera más o menos acorde a su ubicación geográfica real, la Ermita de los Mártires se encuentra mal localizada entre el arrabal de los Percheles y el cauce del río, cuando le correspondería hallarse anexa la Huerta de las Tres Cruces por el lado izquierdo. Pero esta ubicación la dejaría fuera del campo visual que abarca la composición, encontrándose ahí quizá la razón de un desajuste tan evidente. El lugar equívoco que le confiere López Calderón resalta precisamente el pequeño edificio y la importante escena que lo acompaña, haciéndolos más visibles en el cuadro, sobre el rostro de la santa. Por tanto, se observa cómo el pintor sacrifica de manera premeditada, una vez más, la veraz relación de los espacios y tiempos para poder destacar aquellos elementos que le son más importantes en su relato pictórico.

\section{Iglesia de Santo Domingo (fig. I6) y 5. Barrio de los Percheles (fig. I7)}

En la misma margen del Guadalmedina quedaban los arrabales de la Trinidad, más cercano a Martiricos, y del Perchel o de los Percheles, más hacia la desembocadura del río. Enclaves históricamente habitados, extramuros de la ciudad, donde el caserío disperso se mezclaba con numerosas huertas y corrales. Hoy muy transformados, mantienen aún su nombre y algunos de sus edificios más representativos, como los conventos en torno a los cuales nacieron. El de la Trinidad toma de hecho su nombre del cenobio homónimo, cuya fundación se remonta y vincula a la conquista cristiana de la ciudad..$^{\circ \circ}$ El de los Percheles, cercano al mar y de fuerte tradición pesquera, debe su nombre a las muchas perchas o largos palos sobre los que colgaban y secaban los pescados para su comer-

89. Reder Gadow, Los Patronos de Málaga, IO4-IO5.

90. Rosario Camacho, coord., Guía histórico-artística de Málaga (Málaga: Arguval, 2006), $4 I 8$ y 424 . 
I6. Pedro López Calderón,

San Ciriaco y santa Paula (detalle de la iglesia de Santo Domingo). Foto: José Ignacio Mayorga Chamorro. Secretaría de Cultura.-INAH. Méx.-

"Reproducción autorizada por el Instituto Nacional de Antropología e Historia”.

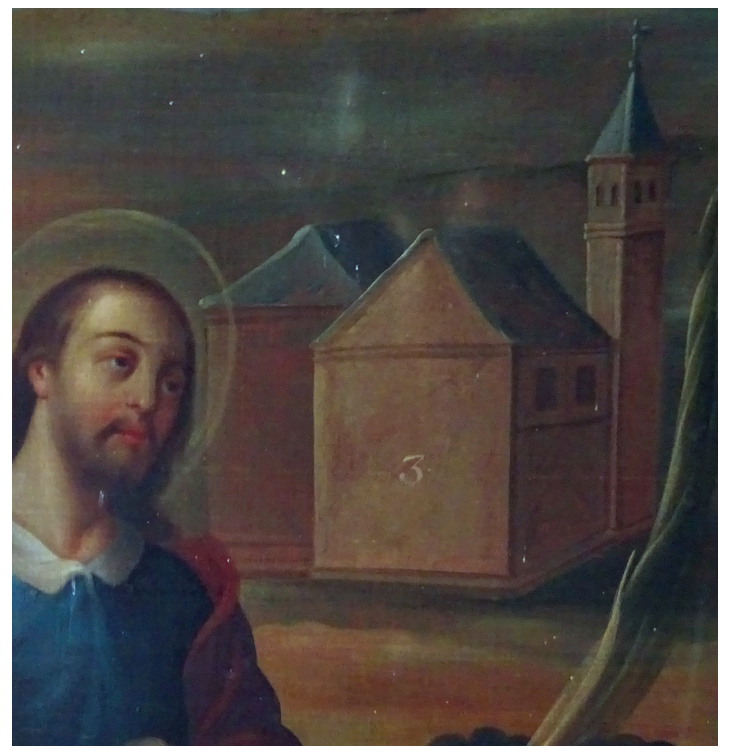

cialización en salazones. ${ }^{91}$ En él había dos grandes conventos desde el siglo XVI, de los que quedan pocos restos salvo sus iglesias, muy modificadas desde entonces: el de predicadores de Santo Domingo y el carmelita de San Andrés. El dominico se fundó en los años inmediatos a la Reconquista y se construyó en I5I8. Su fábrica gótico-mudéjar se transformó durante el barroco, con largos trabajos que terminaron hacia I729, por lo que en fechas de ejecución del lienzo aún se encontraría en reconstrucción. ${ }^{92}$ El pequeño edificio con campanario pintado en esta tela, en poco se parece a la amplia fábrica malagueña, culminada en espadaña. Por tanto, se constata cómo Pedro López Calderón recurrió una vez más a imágenes tipificadas para retratar unos enclaves que no conocía personalmente.

El recurso resulta por completo lógico, pero no lo es tanto la inclusión de tales enclaves, que en principio no tienen conexión alguna con la leyenda de estos mártires. Su único vínculo sería la pertenencia al entorno cercano al río Guadalmedina y a la zona que por tradición se relaciona con el martirio de Ciriaco y Paula. Pero se podría preguntar por qué, en dicho caso, se identifica

91. Camacho, Guía histórico-artística de Málaga, 427-428.

92. Camacho, Guía histórico-artística de Málaga, 430-431. 
expresamente tales elementos en la numeración de la cartela, situándolos así, además, al mismo nivel de aquellos que sí se vinculan con la historia de los Martiricos. ¿Será, acaso, petición expresa del comitente de la obra, que pudiera tener algún tipo de vinculación con la iglesia o los otros enclaves que se citan? ¿por qué otra razón se incluirían e identificarían con tanta precisión? Más aún, teniendo en cuenta que se dejan fuera del lienzo otros elementos que sí están más vinculados a la leyenda de Ciriaco y Paula, como es el monasterio de Nuestra Señora de los Ángeles. En este otro enclave, ligado al entorno de Martiricos por el arroyo que lo cruza y toma su nombre, se llegó a afirmar que estaban enterrados los jóvenes mártires y se conserva, además, un pequeńo monumento con inscripción epigráfica que lo testimonia desde su fundación en el siglo Xvi. ${ }^{93}$ Por ello, su ausencia resulta tan difícil de justificar como la presencia de los Percheles y del templo dominicano.

Considerados todos estos factores, es posible deducir que Pedro López Calderón sólo pudo conocer algunos de los elementos que ahí representa por medio de la descripción e instrucciones que le propiciara un personaje natural de Málaga o al menos buen conocedor de la ciudad y de este entorno particular de su extrarradio. Y éste habría de ser, quizás, el comitente de la obra, a quien se intuye como un malagueño trasladado al virreinato novohispano y enriquecido, que hubiera querido encargar un recuerdo de su ciudad por medio de la imagen de sus santos patronos, de los que además pudiera ser devoto.

En todo caso, y aceptando la hipótesis anterior, no cabría descartar el uso complementario de fuentes escritas, que pudiera haber facilitado el promotor junto al propio conocimiento que él mismo pudiera tener de la leyenda por transmisión popular. De los textos difundidos con anterioridad a I716, sólo es posible considerar aquellos que los toman por naturales de Málaga, como hace el lienzo. Se descartan, además, los citados martirologios, cuyas breves anotaciones en ningún caso abarcan la información presentada por Pedro López Calderón. Su obra presenta detalles que necesariamente beben de la leyenda popular malagueña propia de la Edad Moderna. De la misma, se escribieron y publicaron escasas versiones, que pudieron llegar hasta América, por fecha y relevancia, sólo la del padre Martín de Roa, de 1622,94 y la compuesta por el jesuita Pedro Morejón hacia I676.95 La transcripción y al análisis detallado

93. Reder Gadow, Los Patronos de Málaga, IO2-103.

94. Roa, Málaga, 65-66.

95. Morejón, Historia general, I43-160. 
I7. Pedro López Calderón, San Ciriaco y santa Paula (detalle del barrio de los Percheles). Foto: José Ignacio Mayorga Chamorro. Secretaría de Cultura.-Inah. Méx.-

"Reproducción autorizada por el Instituto Nacional de Antropología e Historia”.

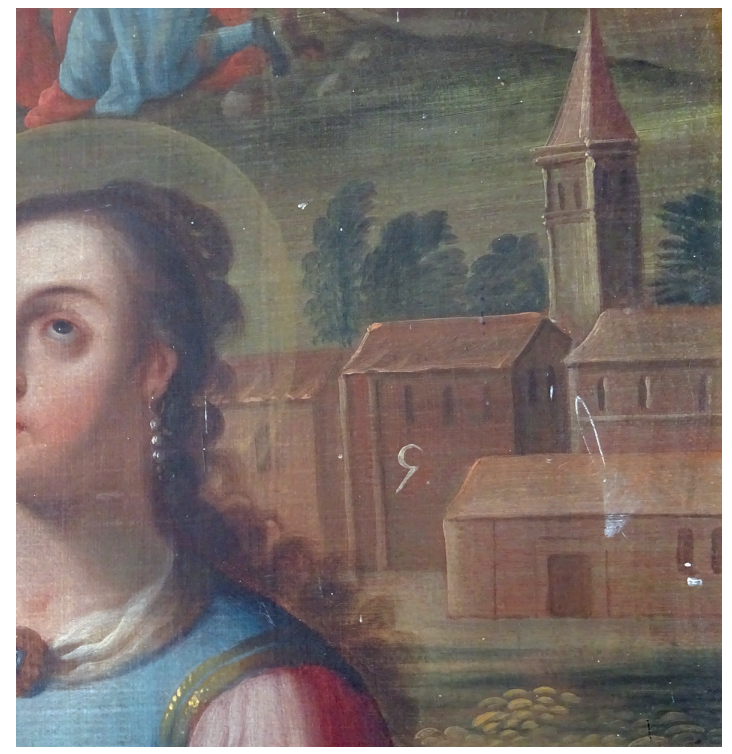

de ambos textos al completo excedería los límites de este artículo, pero conviene detenerse en el de Pedro Morejón como fuente escrita más probable para este lienzo, de existir alguna, por los detalles que siguen.

En primer lugar, Morejón presenta a los santos como "patronos y felicísimos hijos y naturales de Málaga", ${ }^{96}$ coincidiendo el primer y último de los calificativos con los que emplea López Calderón en la cartela. Les proclama además "ymitadores en su martirio al ynbicto capitan y primicia de los mártires san Esteban", ${ }^{97}$ lo cual explicaría que en la escena de su lapidación, Pedro López Calderón recurra a la tradición iconográfica más habitual para este protomártir y no a la tradición local de los santos malagueńos. Y sigue: "que coronados de eterna diadema de gloria triunfan en la corte de la felicidad de los justos", 98 lo cual se refleja a su vez en el carácter triunfante y en los nimbos con que se presentan en el primer plano del lienzo novohispano. Tras esto, añade: "Nacieron estos dos generosos guerreros en Malaga de padres christianos, de alto y claro linaje, pues fueron parientes de los centuriones", ${ }^{99}$ lo que explica la cali-

96. Morejón, Historia general, I45.

97. Morejón, Historia general, I45.

98. Morejón, Historia general, I45.

99. Morejón, Historia general, I45. 
dad de los vestidos y las joyas que portan sus retratos en el lienzo, en especial la santa. Y después de citar sus fuentes y otros datos, expone: "El lugar de sus batallas y el anfiteatro de sus coronas fueron las sedientas arenas del Alguamedina, donde ni el cruxido de las ondas, ni el arrojo de las piedras, ni la rabia de los berdugos [sic] pudieron atemorizar la constancia de aquellos generosos pechos". ${ }^{100}$ La descripción de la escena de la lapidación encuentra también su correspondencia en el lienzo, en particular en las actitudes atribuidas a unos y otros personajes. Pero, sobre todo, destaca el empleo del término Alguamedina, que era una manera propia del momento pero menos frecuente de referirse al río Guadalmedina. Tanto, que es éste el único documento referido a san Ciriaco y santa Paula en el que se emplea dicha denominación, un hecho que explica cómo pudo el pintor llegar a referirla de basarse en fuentes escritas.

Más adelante, Pedro Morejón relata cómo las aguas de dicho río, en sus fuertes crecidas, respetaron siempre la ermita, como signo providencial de reverencia al lugar del martirio. Su relato incluye una referencia expresa a la huerta vecina al templo, a los árboles sembrados en ella y a las vastas y firmes paredes que la cercaban, tal como se reproduce en el lienzo de Calderón. Así,

Esplaiandose las furiosas aguas del Agualmedina por toda aquella anchísima plaia y llanura, llegaron los ímpetus de sus raudales quatro o seis varas de la hermita, y como teniendo respeto a sus paredes, se detubieron aziendo una como balla tan alta que casi ygualaba la altura de unos morales que se ven alrededor de de aquella hermita, sin atraverse a pasar más adelante, ${ }^{\text {IOI }}$

pero la cólera de las aguas "hizo grande estrago en una huerta mui vecina a la hermita, sacando de la tierra asta las ultimas raízes de los arboles de que estaba poblada, y atropellando las paredes vastamente firmes de la misma huerta" ${ }^{\text {IO2 }}$

Este cúmulo de paralelos hace que se pueda considerar al texto de Pedro Morejón como probable fuente de información para Pedro López Calderón, aun suponiendo, además, las aportaciones añadidas de un informador malagueño, que probablemente fuera el comitente. Sólo considerando ambas fuentes se justifica que un pintor novohispano, del que no se conocen estancias en Málaga o España, pudo conocer una iconografía restringida a lo local, la cual

IOo. Morejón, Historia general, I46.

IOI. Morejón, Historia general, I5I.

IO2. Morejón, Historia general, I5I. 
supo reformular desligándose de la tradición artística de origen, para ofrecer un resultado original e innovador con base en recursos propios y de la plástica barroca novohispana.

Con este ejercicio, Pedro López Calderón muestra, una vez más, su habilidad para la formulación de soluciones iconográficas ricas y complejas, en la línea de lo ya avanzado por los escasos estudios dedicados a su obra. El lienzo presentado es un ejemplo de la calidad artística que llegó a alcanzar el pintor en fechas muy tempranas de su producción; asimismo, confirma una dispersión geográfica de su trabajo mayor a la tradicionalmente considerada (circunscrita a la capital y el septentrión virreinal), y a la vez contribuye, de manera general, al mejor conocimiento y la necesaria puesta en valor de la pintura novohispana del siglo XVIII. ${ }^{\mathrm{IO}}$

I03. Investigación financiada por el Ministerio de Educación, Cultura y Deporte de España en su programa de Ayudas para la Formación de Profesorado Universitario y por la Universidad de Málaga-Campus de Excelencia Internacional Andalucía Tech. 